ISSN 0103-9954

\title{
MODIFICAÇÕES FLORÍSTICO-ESTRUTURAIS DE UM REMANESCENTE DE FLORESTA OMBRÓFILA MISTA MONTANA NO PERÍODO ENTRE 1979 E 2000
}

\section{FLORISTIC AND STRUCTURAL CHANGES IN AN OMBROPHYLLOUS MIXED FOREST BETWEEN THE YEARS 1979 AND 2000}

\author{
Luciano Budant Schaaf ${ }^{1}$ Afonso Figueiredo Filho ${ }^{2}$ Franklin Galvão ${ }^{3}$ \\ Carlos Roberto Sanquetta ${ }^{3}$ Solon Jonas Longhi ${ }^{4}$
}

\section{RESUMO}

Com o objetivo de estudar as alterações florísticas e estruturais ocorridas em uma Floresta Ombrófila Mista, localizada na Estação Experimental da UFPR (São João do Triunfo-PR), nove parcelas de 1 ha cada, avaliadas inicialmente em 1979, foram remedidas em 2000. Em 1979, todos os indivíduos arbóreos com DAP igual ou superior a $20 \mathrm{~cm}$ foram identificados e etiquetados e tiveram as suas alturas total e comercial e o diâmetro medidos. Em 2000, usando os mesmos critérios de inclusão, os indivíduos que não haviam sido computados em 1979 foram considerados como ingressos e os não-encontrados como mortos. Em 1979, foram encontradas 2.133 indivíduos, 51 espécies e 29 famílias. No levantamento realizado em 2000, foram encontradas 2.202 indivíduos, 55 espécies e 31 famílias. As famílias Araucariaceae, Aquifoliaceae, Lauraceae, Sapindaceae, Myrtaceae e Canellaceae foram as mais expressivas em termos de quantidade de indivíduos em ambos os levantamentos. Embora nas duas ocasiões, houvesse mais que cinquenta espécies, apenas sete espécies (Araucaria angustifolia, Ilex dumosa, Matayba elaeagnoides, Ocotea porosa, Capsicodendron dinisii, Nectandra grandiflora e Campomanesia xanthocarpa) representavam 80,4\% dos indivíduos em 1979 e, no ano 2000, as mesmas sete espécies acrescidas de Ocotea corymbosa responderam por $80,9 \%$ do número total de indivíduos. Hovenia dulcis (uva-do-japão), espécie exótica, pelo número de indivíduos adultos e de regeneração, passou a configurar como uma invasora importante do ecossistema. Todos os indicadores estruturais analisados mostraram que a comunidade amadureceu no período estudado e que Araucaria angustifolia acentuou sua dominância. Houve um aumento sensível no grau de ocupação,

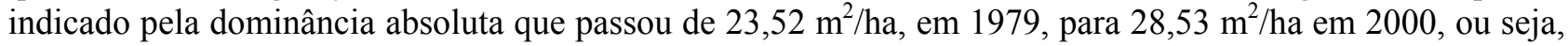
houve um aumento de $21,3 \%$. Isso indica que essa comunidade está em processo de desenvolvimento, ainda não se encontrando completamente estocada. Ficou evidenciado também que a dominância da araucária se acentuou no período, sendo bem provável que tal dominância venha a aumentar ainda mais no futuro. Em relação à diversidade, observou-se que os índices que consideram tanto a quantidade de espécies (riqueza) como a uniformidade da distribuição da densidade, ou seja, os índices de Simpson, $U$ e $D$ de McIntosh, são os que melhor representam as alterações ocorridas no período.

Palavras-chave: floresta com araucária; fitossociologia; dinâmica; diversidade florística; índices de riqueza.

\section{ABSTRACT}

The floristic and structure alterations were studied in an Ombrophyllous Mixed Forest located in São João do Triunfo (Paraná State - Brazil). Nine plots of 1ha, first evaluated in 1979, were recovered and, measured in 2000. In 1979, all the trees with $d b h \geq 20 \mathrm{~cm}$ were identified and tagged, and they had their commercial height and diameter measured. In 2000, based on the same criteria described before, the trees which had not been counted in 1979 were considered as ingrowth, and the missing ones were considered mortality. In 1979, 2133 individuals, 51 species and 29 families were found and in the 2000 survey, 2202

1. Engenheiro Florestal, MSc., Pós-Graduado pelo Programa de Pós-Graduação em Engenharia Florestal, Universidade Federal do Paraná, Rua Lothário Meissner, 3400, Jardim Botânico, CEP 80210-170, Curitiba (PR). forester@onda.com.br

2. Engenheiro Florestal, Dr., Professor da Universidade Federal do Centro Oeste e do Programa de Pós-Graduação em Engenharia Florestal Universidade Federal do Paraná, Rua Lothário Meissner, 3400, Bairro Jardim Botânico, CEP 80210-170, Curitiba (PR). afonso@irati.unicentro.br

3. Engenheiro Florestal, Dr., Professor do Departamento de Ciências Florestais, Universidade Federal do Paraná, Rua Lothário Meissner, 3400, Bairro Jardim Botânico, CEP 80210-170, Curitiba (PR). fgalvao@floresta.ufpr.br/sanquetta@floresta.ufpr.br

4. Engenheiro Florestal, Dr., Professor Titular do Departamento de Ciências Florestais, Centro de Ciências Rurais, Universidade Federal de Santa Maria, Campus Universitário, CEP 97105-900, Santa Maria (RS). solon.longhi@pesquisador.cnpq.br

Recebido para publicação em 26/06/2005 e aceito em 16/08/2006. 
individuals, 55 species and 31 families ware journal. In both surveys, the families Araucariaceae, Aquifoliaceae, Lauraceae, Sapindaceae, Myrtaceae and Canellaceae were the most represented in terms of quantity of individuals. Although in both times more than 50 species were counted, in 1979 only 7 species (Araucaria angustifolia, Ilex dumosa, Matayba elaeagnoides, Ocotea porous, Capsicodendron dinisii, Nectandra grandiflora and Campomanesia xanthocarpa) represented $80.4 \%$ of the individuals and, in 2000, the same 7 species plus Ocotea corymbosa covered $80.9 \%$ of the total number of individuals. Hovenia dulcis, exotic specie, based on the number of adult and regeneration individuals, became to be seen as a threat to the autocnons species. All the structural indicators which were analyzed showed that the community has become more mature during the studied period and that the Araucaria angustifolia increased its dominance. There was a sensible increase of the occupancy grade, indicated by the absolutely dominance that changes from $23.52 \mathrm{~m}^{2} /$ ha in 1979 , to $28.53 \mathrm{~m}^{2} /$ ha, in 2000 , an increase of $21.3 \%$. These results indicate that this community is still in development, and has not yet found its equilibrium. It also demonstrates that the Araucaria dominance increased in this period, suggesting that this profile can even increase future in the future. Regarding to the diversity, it was observed that the indices that consider, the amount of species (richness) and the homogeneity of the density distribution (the indexes of Simpson, $U$ and $D$ of McIntosh) are the ones that best represent the alterations of the period.

Keywords: araucaria forest; phytosociology; forest dynamic; floristic diversity; richness indexes.

\section{INTRODUÇÃO}

O homem tem, desde as mais remotas eras, utilizado os recursos florestais para sua sobrevivência. No entanto, nos últimos 50 anos a magnitude e a velocidade das alterações têm provocado evidentes influências negativas na qualidade ambiental do planeta, além de reduzir drasticamente a diversidade biológica.

No Brasil, uma parte significativa da vegetação original, e entre elas a da Floresta Ombrófila Mista ou Floresta com Araucária (Leite e Klein, 1990), foi reduzida a fragmentos alterados e descaracterizados antes mesmo de ser adequadamente conhecida. A Floresta Ombrófila Mista, originalmente com ocorrência contínua nos planaltos do sul e disjunta na Região Sudeste do Brasil, teve sua superfície drasticamente reduzida restando, dos estimados $177.000 \mathrm{~km}^{2}$ (Leite e Klein, 1990), apenas 1 a $\%$, de acordo com as análises mais otimistas (Kock e Corrêa, 2002). Nos $200.000 \mathrm{~km}^{2}$ do estado do Paraná, essa unidade fitoecológica teve sua superfície original de $37 \%$ reduzida para $0,8 \%$ (cerca de $1.600 \mathrm{~km}^{2}$ ), representada por um estágio avançado de conservação com elevada biodiversidade, de acordo com um levantamento recente realizado pela Fundação de Pesquisas Florestais do Paraná - FUPEF (Castella e Britez, 2004).

Essas informações indicam a real gravidade da situação, evidenciando a necessidade do estabelecimento de rotinas para obtenção de informações científicas com o propósito de entender a complexidade desse ecossistema e de auxiliar na recuperação de remanescentes.

A maneira mais adequada de compreender a composição florística, estrutura, crescimento, mortalidade e ingresso de uma comunidade é monitorá-la sistematicamente por longo período. Goldsmith e Harrison (1976) afirmaram que mudanças na vegetação em longos períodos são melhor estudadas por meio de parcelas permanentes ou de transectos permanentes. Todavia, a instalação e, sobretudo, o monitoramento dessas parcelas podem ser considerados fatos recentes no Brasil, especialmente se comparados à velocidade com que os processos dinâmicos e a eliminação das florestas ocorrem.

A composição florística de uma floresta pode ser expressa por meio de sua diversidade. Um dos conceitos mais antigos e elementares de diversidade é citado por Kimmins (1987), o qual descreveu que "a diversidade refere-se ao número de espécies diferentes que ocorrem na comunidade". Contudo, para o mesmo autor, a diversidade expressa em termos de uma lista de espécies não fornece um quadro adequado da comunidade, porque a abundância e a importância relativa das espécies podem variar.

Para Hulbert (1971) e Odum (1988), o conceito de diversidade de espécies possui dois componentes: a riqueza, também chamada de densidade de espécies, baseada no número total de espécies presentes, e a uniformidade, baseada na abundância relativa (ou em outra medida de 'importância') de espécies e no grau de sua dominância, ou falta desta.

Longhi (1980) utilizou um dos índices de diversidade mais simples de ser obtido, o quociente de 
mistura de Jentsch, para medir a intensidade de mistura de espécies e a heterogeneidade florística da floresta em questão.

Segundo Peet (1974), alguns índices têm sido empregados como medida da riqueza das espécies, independente do tamanho da amostra. Tais índices pressupõem uma relação funcionalparticular entre o número de espécies $(S)$ observado e o tamanho da amostra $(N)$ e desse modo, o valor dos índices muda de uma comunidade para outra, contudo, a relação não.

Para Longhi (1980), os resultados das análises estruturais permitem fazer deduções sobre a origem, características ecológicas e sinecológicas, dinamismo e tendência do futuro desenvolvimento das florestas, elementos básicos para o planejamento da condução silvicultural. O mesmo autor, em conformidade com Lamprecht (1964), descreveu que embora haja grande variação nos métodos de análise estrutural e não exista uniformidade internacional, os requisitos que devem ser observados para que o método seja utilizado de forma satisfatória são:

a) capacidade de expressar a estrutura do tipo de floresta estudada;

b) aplicação em qualquer tipologia de floresta;

c) geração de resultados objetivos, livres de influências subjetivas, sendo desejável que sejam expressos por cifras e números;

d) resultados de diferentes análises procedentes do mesmo ou de distintos tipos florestais sejam diretamente comparáveis;

e) possibilidade de aplicação de análise estatística.

A estrutura horizontal, em geral, tem sido avaliada por vários autores por meio da densidade, freqüência, dominância, índice de valor de importância e índice de valor de cobertura.

Nesta pesquisa, parcelas permanentes foram utilizadas para avaliar as alterações florísticas e estruturais ocorridas em uma Floresta Ombrófila Mista Montana no período de 21 anos, entre 1979 e 2000.

\section{MATERIAL E MÉTODOS}

\section{Características da área de estudo}

Este estudo foi feito na Estação Experimental da Universidade Federal do Paraná, localizada no município de São João do Triunfo (a cerca de $125 \mathrm{~km}$ de Curitiba), estado do Paraná, Brasil, no Segundo Planalto, a $780 \mathrm{~m}$, entre as coordenadas $25^{\circ} 34^{\prime} 18^{\prime \prime} \mathrm{S}$ e $50^{\circ} 05^{\prime} 56^{\prime \prime} \mathrm{W}$. A floresta tem uma área total de 32,36 ha, dividida em 32 parcelas de 1 ha $(100 \mathrm{~m}$ x $100 \mathrm{~m})$ cada, e essa, em cem subparcelas de $10 \mathrm{~m}$ x $10 \mathrm{~m}$.

De acordo com a classificação climática de Köppen, a região apresenta clima do tipo $C f b$ (Longhi, 1980; Rodríguez Tello, 1980; Pizatto, 1999; Durigan, 1999), caracterizado por ser mesotérmico, sempre úmido e com verões brandos. O clima é típico do planalto meridional brasileiro, com temperaturas médias anuais entre 14 e $19^{\circ} \mathrm{C}$ e precipitação anual entre 1.250 e $2.000 \mathrm{~mm}$. Os dados climáticos médios obtidos das Estações Meteorológicas do IAPAR da Lapa, Fernandes Pinheiro e Ponta Grossa, próximas à área de estudo (adaptado de Durigan, 1999) indicam uma temperatura média anual de $17,4^{\circ} \mathrm{C}$, umidade relativa média anual de $80,1 \%$, precipitação média anual de $1.615 \mathrm{~mm}$, sendo janeiro o mês mais chuvoso e agosto o mais seco.

Segundo Longhi (1980), baseado num levantamento realizado na área, o solo predominante é do tipo Argissolo Vermelho-Amarelo distrófico, sendo encontrado também em pequena proporção Cambissolo distrófico álico.

Durigan (1999), por meio de prospecções realizadas, também nesta Estação Experimental, identificou a ocorrência de Latossolo Vermelho-Escuro e Latossolo Vermelho-Amarelo, além de Cambissolos (Cambissolo gleico, nas cotas mais baixas) e Neossolos Litólicos.

Baseando-se na classificação proposta pelo IBGE (1992), a tipologia vegetal dominante na área é a Floresta Ombrófila Mista Montana que, apesar de não ter sofrido corte raso, é bastante alterada, enquadrando-se como uma vegetação primária alterada ou formação secundária avançada, visto que possui algumas características estruturais de formações primárias associadas a intervenções antrópicas que caracterizam formações secundárias. 
A área foi adquirida em 1969 de colonos da região, tendo sofrido corte seletivo em algumas parcelas (Longhi, 1980). Segundo declarações do Sr. Deonízio Kieras, funcionário responsável pela Estação Experimental desde 1972, a floresta, apesar de não ter sofrido corte raso, foi alterada pelas seguintes intervenções: a) exploração seletiva de araucárias - retirada de indivíduos de grandes dimensões (antes de 1972); b) exploração de erva-mate (antes de 1972); c) corte dos indivíduos mais finos, em algumas parcelas; d) incêndio que afetou as parcelas próximas à estrada em 1982; e) exploração e poda da erva-mate em 1983.

\section{Métodos}

Este estudo se fundamentou no levantamento realizado por Solon Jonas Longhi e Julio César Rodríguez Tello, em 1979, no qual foram coletados dados referentes a todos os indivíduos arbóreos presentes em nove parcelas de um hectare cujo DAP (diâmetro à altura do peito é $1,3 \mathrm{~m}$ ) era igual ou superior a $20 \mathrm{~cm}$. As parcelas 1, 6, 7, 10, 17, 18, 21, 22 e 30 foram selecionadas, com base na abundância de Araucaria angustifolia na fase adulta.

Foram registradas, em 1979, para cada indivíduo, as seguintes informações: nome vulgar, DAP, altura total e comercial, vitalidade e qualidade do fuste (Longhi, 1980). As alturas foram estimadas e os diâmetros obtidos utilizando-se uma suta, com precisão de $0,5 \mathrm{~cm}$. Os indivíduos foram etiquetados com fita rotex e pregos.

Em 2000, usando o mesmo critério de inclusão, todos os indivíduos ocorrentes nas nove parcelas tiveram seus DAP's medidos. Os diâmetros, nessa ocasião, foram obtidos com fita diamétrica ou trena (indivíduos maiores), com precisão de $0,5 \mathrm{~cm}$.

A florística e a estrutura foram analisadas tomando por base as informações resgatadas de 1979 e comparadas às de 2000.

A diversidade de espécies foi determinada mediante o uso de índices de riqueza e de heterogeneidade (quociente de mistura de Jentsch; índice de Margalef; índice de Odum; índice de Menhinick; índice $U$ de McIntosh; índice $D$ de McIntosh e índice de Simpson), conforme Peet (1974) e Odum (1988). Os parâmetros utilizados para descrever a estrutura foram a densidade, freqüência, dominância, valor de cobertura e valor de importância (Mueller-Dumbois e Ellenberg, 1974).

Os cálculos dos índices de diversidade e dos parâmetros que descrevem a estrutura horizontal foram realizados por meio do suplemento para o Microsoft ${ }^{\circledR}$ Excel ${ }^{\circledR}$, denominado Florexel, versão 1.0.4, desenvolvido pelo Prof. Dr. Julio Eduardo Arce do Departamento de Ciências Florestais da Universidade Federal do Paraná.

A classificação taxonômica utilizada na identificação das espécies seguiu o sistema proposto por Cronquist (1981). O material fértil das espécies amostradas foi incorporado ao herbário do Departamento de Ciências Florestais da UFPR por meio dos levantamentos realizados por Longhi (1980), Pizatto (1999) e Durigan (1999). Maiores detalhes sobre a metodologia empregada neste trabalho podem ser consultados em Schaaf (2001).

\section{RESULTADOS E DISCUSSÃO}

\section{Composição florística}

A lista de espécies e famílias, encontrada nos levantamentos de 1979 e de 2000, pode ser observada na Tabela 1.

Em 1979, Longhi (1980) encontrou 51 espécies, com DAP igual ou superior a $20 \mathrm{~cm}$, nas nove parcelas estudadas. Desse total, seis espécies, com 17 indivíduos, não foram identificadas. O autor optou por agrupá-las como uma única espécie, considerando sua reduzida representatividade. Dessa forma, contabilizou no levantamento realizado em 1979, 46 espécies (45 espécies +1 grupo de espécies denominado de "não-identificados"). 
TABELA 1: Composição florística da Floresta Ombrófila Mista de São João do Triunfo, PR nos anos de 1979 e 2000.

TABLE 1: Floristic composition of Ombrophyllous Mixed Forest in Sao Joao do Triunfo, PR, from 1979 to 2000.

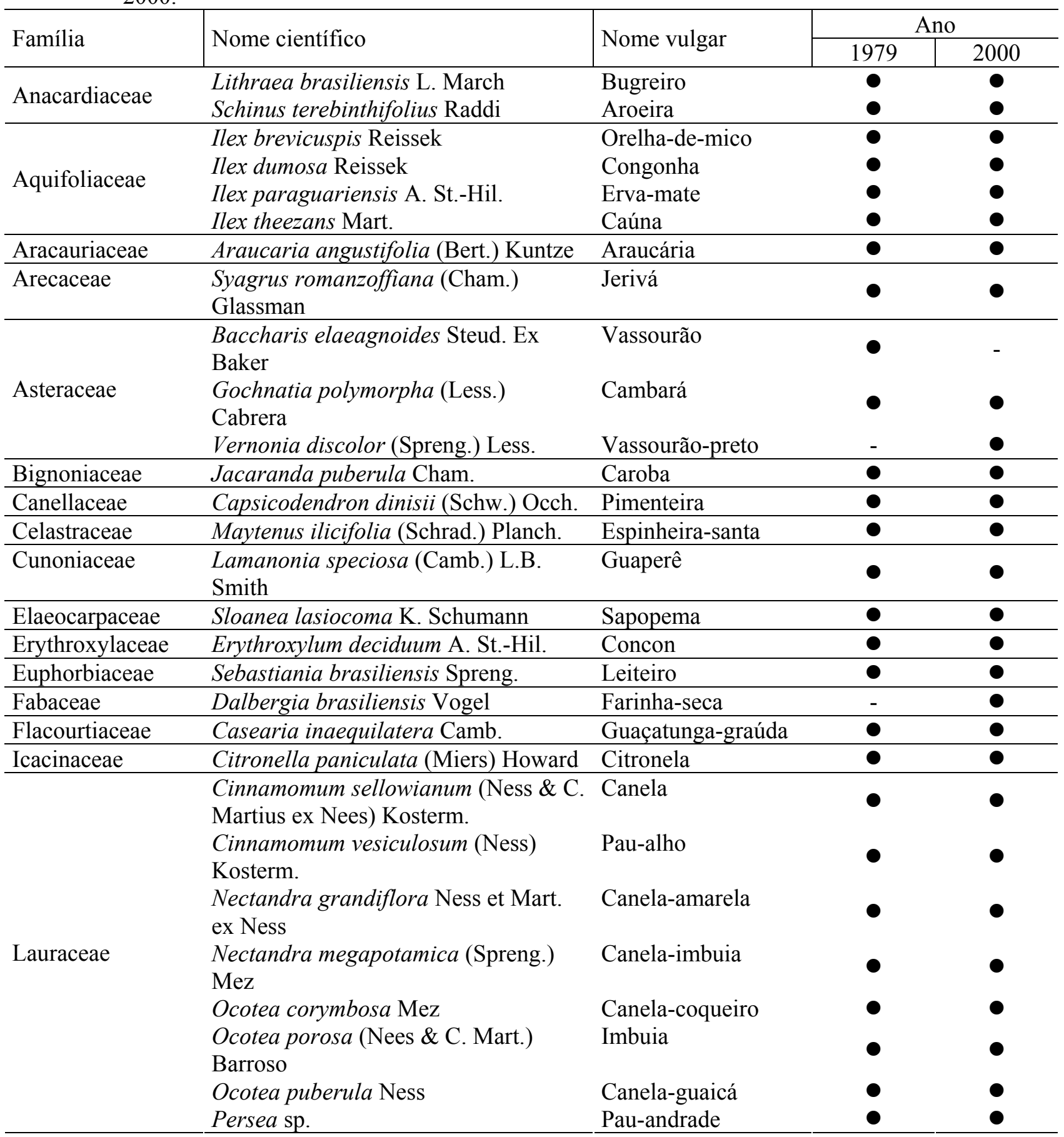

Continua ... 
TABELA 1: Continuação ...

TABLE 1: Continued ...

\begin{tabular}{|c|c|c|c|c|}
\hline \multirow{2}{*}{ Família } & \multirow{2}{*}{ Nome científico } & \multirow{2}{*}{ Nome vulgar } & \multicolumn{2}{|c|}{ Ano } \\
\hline & & & 1979 & 2000 \\
\hline Meliaceae & Cedrela fissilis Vell. & Cedro & $\bullet$ & $\bullet$ \\
\hline Mimosaceae & $\begin{array}{l}\text { Albizia sp. } \\
\text { Mimosa scabrella Benth. }\end{array}$ & $\begin{array}{l}\text { Cuvitinga } \\
\text { Bracatinga }\end{array}$ & $\ddot{\bullet}$ & $\ddot{0}$ \\
\hline Myrsinaceae & $\begin{array}{l}\text { Rapanea ferruginea (Ruiz \& Pav.) } \\
\text { Mez }\end{array}$ & Capororoca & $\bullet$ & - \\
\hline Myrtaceae & $\begin{array}{l}\text { Campomanesia guazumifolia (Camb.) } \\
\text { Berg } \\
\text { Campomanesia xanthocarpa Berg } \\
\text { Eugenia hyemalis Camb. } \\
\text { Eugenia involucrata DC. } \\
\text { Eugenia } \text { sp. } \\
\text { Eugenia speciosa } \text { Camb. } \\
\text { Eugenia uniflora } \text { L. } \\
\text { Gomidesia sellowiana Berg. } \\
\text { Myrcia obtecta (Berg.) Kiaersk. }\end{array}$ & $\begin{array}{l}\text { Guamirim-preto } \\
\text { Solta-capotes } \\
\text { Guabiroba } \\
\text { Guamirim-vermelho } \\
\text { Cerejeira } \\
\text { Murta } \\
\text { Araçá } \\
\text { Pitanga } \\
\text { Guamirim } \\
\text { Cambuí }\end{array}$ & $\begin{array}{l}\bullet \\
\\
- \\
\bullet \\
\bullet \\
\bullet \\
\bullet \\
\bullet \\
\bullet\end{array}$ & $\begin{array}{l} \\
\bullet \\
\bullet \\
\bullet \\
\bullet \\
\bullet \\
\bullet \\
\bullet \\
\bullet\end{array}$ \\
\hline Proteaceae & Roupala brasiliensis Klotz. & Carvalho-brasileiro & - & $\bullet$ \\
\hline Rhamnaceae & $\begin{array}{l}\text { Hovenia dulcis Thunb. } \\
\text { Scutia buxifolia Reissek }\end{array}$ & $\begin{array}{l}\text { Uva-do-japão } \\
\text { Laranjinha-do-mato }\end{array}$ & $\overline{-}$ & $\begin{array}{l}\bullet \\
-\end{array}$ \\
\hline Rosaceae & $\begin{array}{l}\text { Prunus brasiliensis (Cham. \& Schltdl.) } \\
\text { Dietrich }\end{array}$ & Pessegueiro-bravo & • & - \\
\hline Rutaceae & $\begin{array}{l}\text { Zanthoxylum kleinii (R.S. Cowan) } \\
\text { Waterman }\end{array}$ & Juvevê & $\bullet$ & - \\
\hline Sapindaceae & $\begin{array}{l}\text { Allophylus edulis (A. St.-Hil., } \\
\text { Cambess. \& A. Juss.) Radlk. } \\
\text { Cupania vernalis Camb. } \\
\text { Matayba elaeagnoides Radlk. }\end{array}$ & $\begin{array}{l}\text { Vacum } \\
\text { Cuvatã } \\
\text { Miguel-pintado }\end{array}$ & $\begin{array}{l}\bullet \\
- \\
\end{array}$ & $\begin{array}{l}\bullet \\
\bullet \\
\bullet\end{array}$ \\
\hline Styracaceae & Styrax leprosus Hook. \& Arn. & Carne-de-vaca & $\bullet$ & $\bullet$ \\
\hline Symplocaceae & Symplocos tenuifolia Brand & Pau-de-cangalha & $\bullet$ & - \\
\hline Ttiliaceae & Luehea divaricata Mart. et Zucc. & Açoita-cavalo & - & - \\
\hline Verbenaceae & $\begin{array}{l}\text { Vitex megapotamica (Spreng.) } \\
\text { Moldenke }\end{array}$ & Tarumã & $\bullet$ & - \\
\hline Winteraceae & Drimys brasiliensis Miers & Casca-de-anta & $\bullet$ & $\bullet$ \\
\hline Não identificada & Não-identificados & - & - & - \\
\hline
\end{tabular}

No levantamento realizado em 2000, procurou-se identificar os 17 indivíduos não-identificados por Longhi (1980). Contudo, 7 dos 17 já haviam morrido e, entre os demais, dois indivíduos permaneceram como não-identificados.

Portanto, diante da impossibilidade de identificação dos indivíduos mortos e do fato de apenas três indivíduos ( 2 remanescentes +1 ingresso) não terem sido identificados em 2000, optou-se pelo mesmo procedimento utilizado por Longhi (1980), considerando-os como pertencentes a um único grupo, denominado de "não-identificados".

Assim, neste trabalho, considerou-se que, no ano 1979, foram encontradas 51 espécies (50 espécies + 1 grupo de espécies denominado de "não-identificados"). Esses valores extrapolam em nove indivíduos e em cinco espécies informados em 1979 para o mesmo levantamento. A discrepância entre os valores apresentados em 1979 e os obtidos nesse trabalho deve-se a três fatores:

a) verificou-se que nove indivíduos que não constavam dos registros em 1979 provavelmente tinham DAP's superiores a $20 \mathrm{~cm}$ naquela época, o que não os configuraria como ingressos em 2000; 
b) encontrou-se um indivíduo na parcela 18 que foi considerado duas vezes no levantamento efetuado em 1979, evidenciado pela fixação de duas etiquetas com números diferentes e pela existência de dados idênticos;

c) identificaram-se, em 2000, com exceção de apenas dois, todos os indivíduos que, por ocasião do levantamento feito em 1979, foram enquadrados com o status de não-identificados.

As 51 espécies encontradas em 1979 pertenciam a 38 gênereos e a 29 famílias. Embora a maioria das famílias tenha sido representada por uma única espécie, 7 delas foram representadas por mais de uma espécie, com destaque para Myrtaceae, com 9 espécies, Lauraceae, com 8, e Aquifoliaceae, com 4.

No levantamento realizado em 2000, foram encontradas 55 espécies (54 espécies +1 um grupo de espécies denominado de "não-identificados") e 41 gêneros. Das 51 espécies presentes em 1979, duas não foram encontradas em 2000: Baccharis elaeagnoides e Scutia buxifolia. Por outro lado, seis outras espécies ingressaram no período: Vernonia discolor, Dalbergia brasiliensis, Campomanesia guazumifolia, Roupala brasiliensis, Hovenia dulcis e Cupania vernalis, e duas famílias: Proteaceae e Fabaceae.

\section{Estrutura}

A análise dos parâmetros fitossociológicos, nos anos de 1979 e 2000 (Tabelas 2 e 3), conduz a constatar a realidade de que cada vez mais a Araucaria angustifolia se consolida como a espécie mais característica e importante da comunidade estudada. Em 1979 (Tabela 2), ela já era a espécie mais importante, representando $41,82 \%$ do total de indivíduos, $48,10 \%$ da área basal, sendo ainda a espécie mais amplamente distribuída na área (100\% de freqüência absoluta).

TABELA 2: Parâmetros fitossociológicos da Floresta Ombrófila Mista estudada em 1979.

TABLE 2: Phytosociological parameters of the studied Ombrophyllous Mixed Forest in 1979.

\begin{tabular}{|c|c|c|c|c|c|c|c|c|c|}
\hline Espécies & $\mathrm{N}$ & $\begin{array}{c}\text { DA } \\
\text { N/ha }\end{array}$ & $\begin{array}{c}\text { DR } \\
\% \\
\end{array}$ & $\begin{array}{l}\text { DoA } \\
\mathrm{m}^{2} / \mathrm{ha}\end{array}$ & $\begin{array}{c}\text { DoR } \\
\% \\
\end{array}$ & $\begin{array}{c}\text { FA } \\
\% \\
\end{array}$ & $\begin{array}{c}\text { FR } \\
\% \\
\end{array}$ & V I & V C \\
\hline Araucaria angustifólia & 892 & 99,11 & 41,82 & 11,3155 & 48,10 & 100,00 & 12,13 & 102,05 & 89,92 \\
\hline Ilex dumosa & 279 & 31,00 & 13,08 & 1,9636 & 8,35 & 85,56 & 10,38 & 31,80 & 21,43 \\
\hline Matayba elaeagnoides & 192 & 21,33 & 9,00 & 2,4258 & 10,31 & 72,22 & 8,76 & 28,07 & 19,31 \\
\hline Ocotea porosa & 81 & 9,00 & 3,80 & 1,7500 & 7,44 & 57,78 & 7,01 & 18,24 & 11,24 \\
\hline Capsicodendron dinisii & 104 & 11,56 & 4,88 & 0,9513 & 4,04 & 60,00 & 7,28 & 16,20 & 8,92 \\
\hline Nectandra grandiflora & 90 & 10,00 & 4,22 & 0,8803 & 3,74 & 47,78 & 5,80 & 13,76 & 7,96 \\
\hline Campomanesia xanthocarpa & 76 & 8,44 & 3,56 & 0,5028 & 2,14 & 54,44 & 6,60 & 12,30 & 5,70 \\
\hline Ilex brevicuspis & 64 & 7,11 & 3,00 & 0,7564 & 3,22 & 34,44 & 4,18 & 10,39 & 6,22 \\
\hline Ocotea corymbosa & 36 & 4,00 & 1,69 & 0,6222 & 2,65 & 26,67 & 3,23 & 7,57 & 4,33 \\
\hline Lithraea brasiliensis & 40 & 4,44 & 1,88 & 0,3054 & 1,30 & 31,11 & 3,77 & 6,95 & 3,17 \\
\hline Rapanea ferruginea & 38 & 4,22 & 1,78 & 0,2610 & 1,11 & 24,44 & 2,96 & 5,86 & 2,89 \\
\hline Prunus brasiliensis & 33 & 3,67 & 1,55 & 0,2229 & 0,95 & 22,22 & 2,70 & 5,19 & 2,49 \\
\hline Eugenia involucrata & 23 & 2,56 & 1,08 & 0,1501 & 0,64 & 21,11 & 2,56 & 4,28 & 1,72 \\
\hline Eugenia sp. & 18 & 2,00 & 0,84 & 0,0875 & 0,37 & 16,67 & 2,02 & 3,24 & 1,22 \\
\hline Myrcia obtecta & 14 & 1,56 & 0,66 & 0,1179 & 0,50 & 13,33 & 1,62 & 2,77 & 1,16 \\
\hline Ocotea puberula & 13 & 1,44 & 0,61 & 0,1334 & 0,57 & 12,22 & 1,48 & 2,66 & 1,18 \\
\hline Zanthoxylum kleinii & 12 & 1,33 & 0,56 & 0,0989 & 0,42 & 12,22 & 1,48 & 2,47 & 0,98 \\
\hline Cinnaтотит vesiculosum & 10 & 1,11 & 0,47 & 0,1131 & 0,48 & 10,00 & 1,21 & 2,16 & 0,95 \\
\hline Erythroxylum deciduum & 10 & 1,11 & 0,47 & 0,0431 & 0,18 & 10,00 & 1,21 & 1,86 & 0,65 \\
\hline Cedrela fissilis & 8 & 0,89 & 0,38 & 0,0719 & 0,31 & 8,89 & 1,08 & 1,76 & 0,68 \\
\hline Não-identificadas & 9 & 1,00 & 0,42 & 0,0561 & 0,24 & 8,89 & 1,08 & 1,74 & 0,66 \\
\hline Ilex paraguariensis & 8 & 0,89 & 0,38 & 0,0397 & 0,17 & 8,89 & 1,08 & 1,62 & 0,54 \\
\hline Nectandra megapotamica & 7 & 0,78 & 0,33 & 0,0751 & 0,32 & 6,67 & 0,81 & 1,46 & 0,65 \\
\hline Eugenia speciosa & 6 & 0,67 & 0,28 & 0,0772 & 0,33 & 6,67 & 0,81 & 1,42 & 0,61 \\
\hline
\end{tabular}


TABELA 2: Continuação ...

TABLE 2: Continued ...

\begin{tabular}{|c|c|c|c|c|c|c|c|c|c|}
\hline Espécies & $\mathrm{N}$ & $\begin{array}{c}\text { DA } \\
\text { N/ha }\end{array}$ & $\begin{array}{c}\text { DR } \\
\% \\
\end{array}$ & $\begin{array}{c}\text { DoA } \\
\mathrm{m}^{2} / \mathrm{ha}\end{array}$ & $\begin{array}{c}\text { DoR } \\
\% \\
\end{array}$ & $\begin{array}{c}\text { FA } \\
\% \\
\end{array}$ & $\begin{array}{c}\text { FR } \\
\% \\
\end{array}$ & V I & V C \\
\hline Cinnamomum sellowianum & 6 & 0,67 & 0,28 & 0,0727 & 0,31 & 6,67 & 0,81 & 1,40 & 0,59 \\
\hline Allophylus edulis & 7 & 0,78 & 0,33 & 0,0395 & 0,17 & 6,67 & 0,81 & 1,30 & 0,50 \\
\hline Schinus terebinthifolius & 6 & 0,67 & 0,28 & 0,0274 & 0,12 & 6,67 & 0,81 & 1,21 & 0,40 \\
\hline Citronella paniculata & 5 & 0,56 & 0,23 & 0,0348 & 0,15 & 5,56 & 0,67 & 1,06 & 0,38 \\
\hline Ilex theezans & 3 & 0,33 & 0,14 & 0,0237 & 0,10 & 3,33 & 0,40 & 0,65 & 0,24 \\
\hline Syagrus romanzoffiana & 3 & 0,33 & 0,14 & 0,0208 & 0,09 & 3,33 & 0,40 & 0,63 & 0,23 \\
\hline Jacaranda puberula & 3 & 0,33 & 0,14 & 0,0183 & 0,08 & 3,33 & 0,40 & 0,62 & 0,22 \\
\hline Gochnatia polymorpha & 3 & 0,33 & 0,14 & 0,0472 & 0,20 & 2,22 & 0,27 & 0,61 & 0,34 \\
\hline Sebastiania brasiliensis & 3 & 0,33 & 0,14 & 0,0128 & 0,05 & 3,33 & 0,40 & 0,60 & 0,19 \\
\hline Guamirim-preto & 3 & 0,33 & 0,14 & 0,0120 & 0,05 & 3,33 & 0,40 & 0,60 & 0,19 \\
\hline Eugenia hyemalis & 3 & 0,33 & 0,14 & 0,0116 & 0,05 & 3,33 & 0,40 & 0,59 & 0,19 \\
\hline Casearia inaequilatera & 3 & 0,33 & 0,14 & 0,0344 & 0,15 & 2,22 & 0,27 & 0,56 & 0,29 \\
\hline Mimosa scabrella & 3 & 0,33 & 0,14 & 0,0336 & 0,14 & 2,22 & 0,27 & 0,55 & 0,28 \\
\hline Persea sp. & 2 & 0,22 & 0,09 & 0,0244 & 0,10 & 2,22 & 0,27 & 0,47 & 0,20 \\
\hline Gomidesia sellowiana & 3 & 0,33 & 0,14 & 0,0123 & 0,05 & 2,22 & 0,27 & 0,46 & 0,19 \\
\hline Lamanonia speciosa & 2 & 0,22 & 0,09 & 0,0106 & 0,04 & 2,22 & 0,27 & 0,41 & 0,14 \\
\hline Eugenia uniflora & 2 & 0,22 & 0,09 & 0,0099 & 0,04 & 2,22 & 0,27 & 0,41 & 0,14 \\
\hline Sloanea lasiocoma & 1 & 0,11 & 0,05 & 0,0095 & 0,04 & 1,11 & 0,13 & 0,22 & 0,09 \\
\hline Styrax leprosus & 1 & 0,11 & 0,05 & 0,0095 & 0,04 & 1,11 & 0,13 & 0,22 & 0,09 \\
\hline Drimys brasiliensis & 1 & 0,11 & 0,05 & 0,0092 & 0,04 & 1,11 & 0,13 & 0,22 & 0,09 \\
\hline Vitex megapotamica & 1 & 0,11 & 0,05 & 0,0048 & 0,02 & 1,11 & 0,13 & 0,20 & 0,07 \\
\hline Scutia buxifolia & 1 & 0,11 & 0,05 & 0,0046 & 0,02 & 1,11 & 0,13 & 0,20 & 0,07 \\
\hline Albizia sp. & 1 & 0,11 & 0,05 & 0,0042 & 0,02 & 1,11 & 0,13 & 0,20 & 0,06 \\
\hline Luehea divaricata & 1 & 0,11 & 0,05 & 0,0042 & 0,02 & 1,11 & 0,13 & 0,20 & 0,06 \\
\hline Maytenus ilicifolia & 1 & 0,11 & 0,05 & 0,0040 & 0,02 & 1,11 & 0,13 & 0,20 & 0,06 \\
\hline Baccharis elaeagnoides & 1 & 0,11 & 0,05 & 0,0038 & 0,02 & 1,11 & 0,13 & 0,20 & 0,06 \\
\hline Symplocos tenuifolia & 1 & 0,11 & 0,05 & 0,0035 & 0,01 & 1,11 & 0,13 & 0,20 & 0,06 \\
\hline Total & 2133 & 237,00 & 100,00 & 23,5242 & 100,00 & 824,41 & 100,00 & 300,00 & 200,00 \\
\hline
\end{tabular}

Em que: $\mathrm{N}=$ número de indivíduos amostrados; $\mathrm{DA}=$ densidade absoluta; $\mathrm{DR}=$ densidade relativa; DoA = dominância absoluta; DoR = dominância relativa; FA = freqüência absoluta; FR = freqüência relativa; VI = valor de importância; $\mathrm{VC}=$ valor de cobertura

No período de 21 anos, a araucária não apenas conservou sua importância como a ampliou. Em 2000 (Tabela 3), a espécie apresentou uma densidade relativa de 48,96\% e uma dominância de $57,75 \%$. De maneira geral, pode-se dizer que de cada dois indivíduos, com diâmetro igual ou superior a $20 \mathrm{~cm}$, um é de araucária e que, de cada $10 \mathrm{~m}^{2}$ ocupados por material lenhoso, $6 \mathrm{~m}^{2}$ são de araucária.

TABELA 3: Parâmetros fitossociológicos da Floresta Ombrófila Mista estudada em 2000.

TABLE 3: Phytosociological parameters of the studied Ombrophyllous Mixed Forest in 2000.

\begin{tabular}{|c|c|c|c|c|c|c|c|c|c|}
\hline Espécies & $\mathrm{N}$ & $\begin{array}{c}\text { DA } \\
\text { N/ha }\end{array}$ & $\begin{array}{c}\text { DR } \\
\% \\
\end{array}$ & $\begin{array}{c}\text { DoA } \\
\mathrm{m}^{2} / \mathrm{ha}\end{array}$ & $\begin{array}{c}\text { DoR } \\
\% \\
\end{array}$ & \begin{tabular}{c|} 
FA \\
$\%$ \\
\end{tabular} & \begin{tabular}{c|} 
FR \\
$\%$ \\
\end{tabular} & VI & $\mathrm{VC}$ \\
\hline Araucaria angustifolia & 1078 & 119,78 & 48,96 & 16,4757 & 57,75 & 100,00 & 11,90 & 118,61 & 106,71 \\
\hline Matayba elaeagnoides & 170 & 18,89 & 7,72 & 2,4696 & 8,66 & 67,78 & 8,07 & 24,45 & 16,38 \\
\hline Nectandra grandiflora & 167 & 18,56 & 7,58 & 1,4636 & 5,13 & 76,67 & 9,13 & 21,84 & 12,71 \\
\hline Ocotea porosa & 83 & 9,22 & 3,77 & 2,2121 & 7,75 & 54,44 & 6,48 & 18,00 & 11,52 \\
\hline Campomanesia xanthocarpa & 113 & 12,56 & 5,13 & 0,8380 & 2,94 & 61,11 & 7,28 & 15,34 & 8,07 \\
\hline Capsicodendron dinisii & 87 & 9,67 & 3,95 & 0,7656 & 2,68 & 53,33 & 6,35 & 12,98 & 6,63 \\
\hline Ocotea corymbosa & 41 & 4,56 & 1,86 & 0,8104 & 2,84 & 28,89 & 3,44 & 8,14 & 4,70 \\
\hline Ilex dumosa & 42 & 4,67 & 1,91 & 0,3303 & 1,16 & 34,44 & 4,10 & 7,17 & 3,07 \\
\hline Lithraea brasiliensis & 37 & 4,11 & 1,68 & 0,2762 & 0,97 & 32,22 & 3,84 & 6,48 & 2,65 \\
\hline
\end{tabular}


TABELA 3: Continuação ...

TABLE 3: Continued ...

\begin{tabular}{|c|c|c|c|c|c|c|c|c|c|}
\hline Espécies & $\mathrm{N}$ & $\begin{array}{c}\text { DA } \\
\text { N/ha }\end{array}$ & $\begin{array}{c}\text { DR } \\
\%\end{array}$ & $\begin{array}{c}\text { DoA } \\
\mathrm{m}^{2} / \mathrm{ha}\end{array}$ & $\begin{array}{c}\text { DoR } \\
\%\end{array}$ & $\begin{array}{c}\text { FA } \\
\%\end{array}$ & $\begin{array}{c}\mathrm{FR} \\
\%\end{array}$ & VI & $\mathrm{VC}$ \\
\hline Prunus brasiliensis & 41 & 4,56 & 1,86 & 0,2964 & 1,04 & 30,00 & 3,57 & 6,47 & 2,90 \\
\hline Rapanea ferruginea & 35 & 3,89 & 1,59 & 0,2841 & 1,00 & 23,33 & 2,78 & 5,36 & 2,59 \\
\hline Ilex paraguariensis & 26 & 2,89 & 1,18 & 0,1100 & 0,39 & 27,78 & 3,31 & 4,87 & 1,57 \\
\hline Eugenia sp. & 29 & 3,22 & 1,32 & 0,1411 & 0,49 & 24,44 & 2,91 & 4,72 & 1,81 \\
\hline Syagrus romanzoffiana & 24 & 2,67 & 1,09 & 0,1589 & 0,56 & 16,67 & 1,98 & 3,63 & 1,65 \\
\hline Cinnamomum vesiculosum & 20 & 2,22 & 0,91 & 0,2003 & 0,70 & 15,56 & 1,85 & 3,46 & 1,61 \\
\hline Ocotea puberula & 17 & 1,89 & 0,77 & 0,2061 & 0,72 & 13,33 & 1,59 & 3,08 & 1,49 \\
\hline Eugenia involucrata & 16 & 1,78 & 0,73 & 0,1259 & 0,44 & 14,44 & 1,72 & 2,89 & 1,17 \\
\hline Myrcia obtecta & 15 & 1,67 & 0,68 & 0,1076 & 0,38 & 14,44 & 1,72 & 2,78 & 1,06 \\
\hline Cinnamomum sellowianum & 14 & 1,56 & 0,64 & 0,1395 & 0,49 & 11,11 & 1,32 & 2,45 & 1,12 \\
\hline Ilex brevicuspis & 10 & 1,11 & 0,45 & 0,1351 & 0,47 & 10,00 & 1,19 & 2,12 & 0,93 \\
\hline Cedrela fissilis & 9 & 1,00 & 0,41 & 0,1299 & 0,46 & 10,00 & 1,19 & 2,05 & 0,86 \\
\hline Nectandra megapotamica & 8 & 0,89 & 0,36 & 0,0925 & 0,32 & 7,78 & 0,93 & 1,61 & 0,69 \\
\hline Zanthoxylum kleinii & 8 & 0,89 & 0,36 & 0,0641 & 0,22 & 7,78 & 0,93 & 1,51 & 0,59 \\
\hline Erythroxylum deciduum & 8 & 0,89 & 0,36 & 0,0434 & 0,15 & 7,78 & 0,93 & 1,44 & 0,52 \\
\hline Hovenia dulcis & 8 & 0,89 & 0,36 & 0,0353 & 0,12 & 7,78 & 0,93 & 1,41 & 0,49 \\
\hline Symplocos tenuifolia & 8 & 0,89 & 0,36 & 0,0585 & 0,21 & 6,67 & 0,79 & 1,36 & 0,57 \\
\hline Gomidesia sellowiana & 7 & 0,78 & 0,32 & 0,0382 & 0,13 & 5,56 & 0,66 & 1,11 & 0,45 \\
\hline Allophylus edulis & 7 & 0,78 & 0,32 & 0,0374 & 0,13 & 5,56 & 0,66 & 1,11 & 0,45 \\
\hline Mimosa scabrella & 9 & 1,00 & 0,41 & 0,0402 & 0,14 & 4,44 & 0,53 & 1,08 & 0,55 \\
\hline Guamirim-preto & 6 & 0,67 & 0,27 & 0,0311 & 0,11 & 5,56 & 0,66 & 1,04 & 0,38 \\
\hline Albizia sp. & 5 & 0,56 & 0,23 & 0,0264 & 0,09 & 5,56 & 0,66 & 0,98 & 0,32 \\
\hline Eugenia speciosa & 4 & 0,44 & 0,18 & 0,0354 & 0,12 & 4,44 & 0,53 & 0,83 & 0,31 \\
\hline Vernonia discolor & 4 & 0,44 & 0,18 & 0,0217 & 0,08 & 4,44 & 0,53 & 0,79 & 0,26 \\
\hline Schinus terebinthifolius & 4 & 0,44 & 0,18 & 0,0198 & 0,07 & 4,44 & 0,53 & 0,78 & 0,25 \\
\hline Eugenia uniflora & 4 & 0,44 & 0,18 & 0,0210 & 0,07 & 3,33 & 0,40 & 0,65 & 0,26 \\
\hline Campomanesia guazumifolia & 4 & 0,44 & 0,18 & 0,0165 & 0,06 & 3,33 & 0,40 & 0,64 & 0,24 \\
\hline Não-identificadas & 3 & 0,33 & 0,14 & 0,0223 & 0,08 & 3,33 & 0,40 & 0,61 & 0,21 \\
\hline Drimys brasiliensis & 3 & 0,33 & 0,14 & 0,0220 & 0,08 & 3,33 & 0,40 & 0,61 & 0,21 \\
\hline Jacarandá puberula & 3 & 0,33 & 0,14 & 0,0210 & 0,07 & 3,33 & 0,40 & 0,61 & 0,21 \\
\hline Sebastiania brasiliensis & 3 & 0,33 & 0,14 & 0,0151 & 0,05 & 3,33 & 0,40 & 0,59 & 0,19 \\
\hline Eugenia hyemalis & 3 & 0,33 & 0,14 & 0,0130 & 0,05 & 3,33 & 0,40 & 0,58 & 0,18 \\
\hline Cupania vernalis & 3 & 0,33 & 0,14 & 0,0125 & 0,04 & 3,33 & 0,40 & 0,58 & 0,18 \\
\hline Casearia inaequilatera & 3 & 0,33 & 0,14 & 0,0433 & 0,15 & 2,22 & 0,26 & 0,55 & 0,29 \\
\hline Gochnatia polymorpha & 2 & 0,22 & 0,09 & 0,0479 & 0,17 & 1,11 & 0,13 & 0,39 & 0,26 \\
\hline Sloanea lasiocoma & 1 & 0,11 & 0,05 & 0,0116 & 0,04 & 1,11 & 0,13 & 0,22 & 0,09 \\
\hline Citronella paniculata & 1 & 0,11 & 0,05 & 0,0094 & 0,03 & 1,11 & 0,13 & 0,21 & 0,08 \\
\hline Persea sp. & 1 & 0,11 & 0,05 & 0,0072 & 0,03 & 1,11 & 0,13 & 0,20 & 0,07 \\
\hline Lamanonia speciosa & 1 & 0,11 & 0,05 & 0,0071 & 0,03 & 1,11 & 0,13 & 0,20 & 0,07 \\
\hline Luehea divaricata & 1 & 0,11 & 0,05 & 0,0069 & 0,02 & 1,11 & 0,13 & 0,20 & 0,07 \\
\hline Roupala brasiliensis & 1 & 0,11 & 0,05 & 0,0067 & 0,02 & 1,11 & 0,13 & 0,20 & 0,07 \\
\hline Styrax leprosus & 1 & 0,11 & 0,05 & 0,0058 & 0,02 & 1,11 & 0,13 & 0,20 & 0,07 \\
\hline Vitex megapotamica & 1 & 0,11 & 0,05 & 0,0055 & 0,02 & 1,11 & 0,13 & 0,20 & 0,06 \\
\hline Maytenus ilicifolia & 1 & 0,11 & 0,05 & 0,0049 & 0,02 & 1,11 & 0,13 & 0,19 & 0,06 \\
\hline Ilex theezans & 1 & 0,11 & 0,05 & 0,0045 & 0,02 & 1,11 & 0,13 & 0,19 & 0,06 \\
\hline Dalbergia brasiliensis & 1 & 0,11 & 0,05 & 0,0038 & 0,01 & 1,11 & 0,13 & 0,19 & 0,06 \\
\hline Total & 2202 & 244,67 & 100,00 & 28,5286 & 100,00 & 839,95 & 100,00 & 300,00 & 200,00 \\
\hline
\end{tabular}

Em que: $\mathrm{N}$ = número de indivíduos amostrados; $\mathrm{DA}=$ densidade absoluta; $\mathrm{DR}=$ densidade relativa; DoA = dominância absoluta; DoR = dominância relativa; FA = freqüência absoluta; $F R=$ freqüência relativa; $\mathrm{VI}=$ valor de importância; $\mathrm{VC}=$ valor de cobertura.

Não obstante as mesmas espécies dominarem a comunidade tanto em 1979 quanto em 2000, houve 
mudanças. Dentre as espécies dominantes, a alteração mais significativa ocorreu com Ilex dumosa. Essa espécie que, em 1979, era a mais freqüente e a mais abundante depois da araucária, em 2000, foi apenas a sétima espécie mais freqüente e dominante, sendo que sua densidade relativa baixou de $13,08 \%$ em 1979 , para $1,16 \%$ em 2000.

Outras variações importantes ocorreram com Ilex paraguariensis que, em 1979, era a $22^{\mathrm{a}}$ espécie mais importante e, em 2000, passou a ser a $12^{\mathrm{a}}$ Por outro lado, outra Aquifoliaceae, Ilex brevicuspis apresentou comportamento semelhante à Ilex dumosa, passando da $8^{\mathrm{a}}$ posição em termos de valor de importância em 1979, para a $20^{\mathrm{a}}$ em 2000.

Outra espécie que aumentou sua importância na floresta no período foi o jerivá (Syagrus romanzoffiana), que da $30^{\mathrm{a}}$ espécie mais importante em 1979, passou a $14^{\mathrm{a}} \mathrm{em} 2000$. Entre as espécies dominantes, Nectandra grandiflora e Campomanesia xanthocarpa foram as que mais aumentaram a participação na floresta, sobretudo em termos de densidade.

Um fato preocupante registrado no período foi constatar que Hovenia dulcis (uva-do-japão), uma espécie originária do Japão, China e Himaláia (Lorenzi et al., 2003), não detectada em 1979, em 2000, com 8 indivíduos, superou muitas nativas, demostrando sua agressividade como invasora ambiental.

O ingresso da uva-do-japão na área ocorreu provavelmente por meio da avifauna, visto que seus frutos são bastante apreciados e há algumas matrizes em propriedades da região. Quanto ao seu sucesso na competição com espécies nativas, provavelmente decorre da ausência dos inimigos e competidores naturais com os quais co-evoluiu (Kimmins, 1987).

Outro fato importante a ser observado é de quanto é relativo o conceito de diversidade baseado na riqueza de espécies. Visto que do número total de 51 espécies encontradas em 1979 (Tabela 2), apenas vinte apresentaram densidade maior que um indivíduo/ha, ou seja, 31 espécies podem ser consideradas como de ocorrência rara. Em 2000, esse quadro não sofreu grandes alterações. Das 55 espécies computadas, somente 21 apresentaram densidade superior a um indivíduo/ha. Desse modo, a despeito do aumento do número de espécies, a proporção de espécies raras aumentou. Além disso, em 1979, sete espécies (Araucaria angustifolia, Ilex dumosa, Matayba elaeagnoides, Ocotea porosa, Capsicodendron dinisii, Nectandra grandiflora e Campomanesia xanthocarpa) representavam $80,36 \%$ dos indivíduos e, no ano 2000, as mesmas sete espécies mais Ocotea corymbosa responderam por $80,88 \%$ do número total de indivíduos. Isso evidencia que mesmo com 55 espécies no ano 2000, apenas oito dominam a floresta.

Ao analisar-se a dominância absoluta nota-se que houve um aumento importante no grau de ocupação da floresta no período, com o valor saltando de 23,52 $\mathrm{m}^{2} / \mathrm{ha} \mathrm{em} 1979$ (Tabela 2) para $28,53 \mathrm{~m}^{2} / \mathrm{ha}$ em 2000 (Tabela 3), ou seja, um aumento de 21,27\%. Isso indica que a floresta ainda está em processo de desenvolvimento, ou seja, em 1979 ainda não estava madura ou completamente estocada.

Quando as parcelas são analisadas isoladamente, como pode ser observado nas Tabelas 4 a 12, verifica-se que as espécies que dominam essa comunidade (Araucaria angustifolia, Ilex dumosa, Matayba elaeagnoides, Ocotea porosa, Capsicodendron dinisii, Nectandra grandiflora e Campomanesia xanthocarpa) ocorrem em todas as parcelas, e estão freqüentemente presentes entre as cinco espécies mais importantes em cada uma das parcelas estudadas tanto em 1979 quanto em 2000.

Araucaria angustifolia é a espécie mais importante, em termos fitossociológicos e fisionômicos, em todas as parcelas, independente do ano do levantamento. Isso demonstra que a sua presença marcante não tem uma distribuição agregada, ou seja, está dispersa em toda a área, justificando o impacto que essa espécie causa na paisagem e na estrutura da Floresta Ombrófila Mista. Todavia, o grau de importância da Araucaria angustifolia é variável entre as parcelas e entre os anos de levantamentos. Por exemplo: na parcela 18, no ano 2000, essa espécie atinge os maiores valores de cobertura e importância $(\mathrm{VC}=140,29$ e VI $=154,58)$; já na parcela 30, no mesmo ano, atinge os menores valores $(\mathrm{VI}=81,58$ e $\mathrm{VC}=72,41)$. 
TABELA 4: Parâmetros fitossociológicos das cinco principais espécies e do total da parcela 1 em 1979 e 2000.

TABLE 4: Phytosociological parameters of the five principal species and of the total from plot 1, in 1979 and 2000.

\begin{tabular}{l|r|r|r|r|r|r|r|r}
\hline Espécies & \multicolumn{1}{c|}{$\begin{array}{c}\text { DA } \\
\text { N/ha }\end{array}$} & $\begin{array}{c}\text { DR } \\
\%\end{array}$ & $\begin{array}{c}\text { DoA } \\
\mathrm{m}^{2} / \mathrm{ha}\end{array}$ & $\begin{array}{c}\text { DoR } \\
\%\end{array}$ & $\begin{array}{c}\text { FA } \\
\%\end{array}$ & $\begin{array}{c}\text { FR } \\
\%\end{array}$ & V I & V C \\
\hline \multicolumn{7}{c}{1979} \\
\hline Araucaria angustifólia & 89,00 & 49,44 & 9,4441 & 56,16 & 100,00 & 15,63 & 121,23 & 105,61 \\
Ilex dumosa & 26,00 & 14,44 & 1,9365 & 11,52 & 90,00 & 14,06 & 40,02 & 25,96 \\
Capsicodendron dinisii & 13,00 & 7,22 & 1,1594 & 6,89 & 60,00 & 9,38 & 23,49 & 14,12 \\
Ocotea porosa & 11,00 & 6,11 & 0,9405 & 5,59 & 50,00 & 7,81 & 19,52 & 11,70 \\
Matayba elaeagnoides & 7,00 & 3,89 & 0,5694 & 3,39 & 40,00 & 6,25 & 13,52 & 7,27 \\
\hline Total & 180,00 & 100,00 & 16,8162 & 100,00 & 640,00 & 100,00 & 300,00 & 200,00 \\
\hline \multicolumn{7}{c}{2000} \\
Araucaria angustifólia & 11,00 & 59,89 & 13,2362 & 68,13 & 100,00 & 16,67 & 144,69 & 128,03 \\
Ocotea porosa & 11,00 & 5,88 & 1,4524 & 7,48 & 50,00 & 8,33 & 21,69 & 13,36 \\
Nectandra grandiflora & 7,00 & 3,74 & 0,6939 & 3,57 & 40,00 & 6,67 & 13,98 & 7,32 \\
Mimosa scabrella & 9,00 & 4,81 & 0,3615 & 1,86 & 40,00 & 6,67 & 13,34 & 6,67 \\
Matayba elaeagnoides & 6,00 & 3,21 & 0,6331 & 3,26 & 40,00 & 6,67 & 13,13 & 6,47 \\
\hline Total & 187,00 & 100,00 & 19,4269 & 100,00 & 600,00 & 100,00 & 300,00 & 200,00 \\
\hline
\end{tabular}

Em que: $\mathrm{DA}=$ densidade absoluta; $\mathrm{DR}=$ densidade relativa; DoA = dominância absoluta; DoR = dominância relativa;

$\mathrm{FA}=$ freqüência absoluta; $\mathrm{FR}=$ freqüência relativa; $\mathrm{VI}=$ valor de importância; $\mathrm{VC}=$ valor de cobertura.

TABELA 5: Parâmetros fitossociológicos das cinco principais espécies e do total da parcela 6 em 1979 e 2000.

TABLE 5: Phytosociological parameters of the five principal species and of the total from plot 6, in 1979 and 2000.

\begin{tabular}{l|r|r|r|r|r|r|r|r}
\hline Espécies & $\begin{array}{c}\text { DA } \\
\text { N/ha }\end{array}$ & $\begin{array}{c}\text { DR } \\
\%\end{array}$ & $\begin{array}{c}\text { DoA } \\
\mathrm{m}^{2} / \mathrm{ha}\end{array}$ & $\begin{array}{c}\text { DoR } \\
\%\end{array}$ & $\begin{array}{c}\text { FA } \\
\%\end{array}$ & $\begin{array}{c}\text { FR } \\
\%\end{array}$ & V I & V C \\
\hline \multicolumn{7}{c}{1979} \\
\hline Araucaria angustifólia & 83,00 & 35,78 & 9,4277 & 44,39 & 100,00 & 12,20 & 92,36 & 80,16 \\
Matayba elaeagnoides & 47,00 & 20,26 & 4,4209 & 20,82 & 100,00 & 12,20 & 53,27 & 41,07 \\
Ilex dumosa & 31,00 & 13,36 & 1,9692 & 9,27 & 100,00 & 12,20 & 34,83 & 22,63 \\
Capsicodendron dinisii & 12,00 & 5,17 & 0,9833 & 4,63 & 50,00 & 6,10 & 15,90 & 9,80 \\
Campomanesia xanthocarpa & 9,00 & 3,88 & 0,5469 & 2,57 & 70,00 & 8,54 & 14,99 & 6,45 \\
\hline Total & 232,00 & 100,00 & 21,2390 & 100,00 & 820,00 & 100,00 & 300,00 & 200,00 \\
\hline \multicolumn{7}{c}{2000} \\
Araucaria angustifolia & 101,00 & 41,22 & 14,1948 & 53,23 & 100,00 & 11,36 & 105,81 & 94,45 \\
Matayba elaeagnoides & 43,00 & 17,55 & 4,3306 & 16,24 & 100,00 & 11,36 & 45,15 & 33,79 \\
Nectandra grandiflora & 23,00 & 9,39 & 1,5408 & 5,78 & 100,00 & 11,36 & 26,53 & 15,17 \\
Campomanesia xanthocarpa & 14,00 & 5,71 & 0,9471 & 3,55 & 80,00 & 9,09 & 18,36 & 9,27 \\
Ilex dumosa & 9,00 & 3,67 & 0,5769 & 2,16 & 50,00 & 5,68 & 11,52 & 5,84 \\
Total & 245,00 & 100,00 & 26,6690 & 100,00 & 880,00 & 100,00 & 300,00 & 200,00 \\
\hline
\end{tabular}

Em que: $\mathrm{DA}=$ densidade absoluta; $\mathrm{DR}=$ densidade relativa; DoA $=$ dominância absoluta; DoR = dominância relativa;

$\mathrm{FA}=$ freqüência absoluta; $\mathrm{FR}=$ freqüência relativa; $\mathrm{VI}=$ valor de importância; $\mathrm{VC}=$ valor de cobertura. 
TABELA 6: Parâmetros fitossociológicos das cinco principais espécies e do total da parcela 7 em 1979 e 2000.

TABLE 6: Phytosociological parameters of the five principal species and of the total from plot 7, in 1979 and 2000.

\begin{tabular}{l|r|r|r|r|r|r|r|r}
\hline Espécies & $\begin{array}{c}\text { DA } \\
\text { N/ha }\end{array}$ & $\begin{array}{c}\text { DR } \\
\%\end{array}$ & $\begin{array}{c}\text { DoA } \\
\mathrm{m}^{2} / \mathrm{ha}\end{array}$ & $\begin{array}{c}\text { DoR } \\
\%\end{array}$ & $\begin{array}{c}\text { FA } \\
\%\end{array}$ & $\begin{array}{c}\text { FR } \\
\%\end{array}$ & V I & V C \\
\hline Araucaria angustifolia & 154,00 & 63,90 & 16,2988 & 74,21 & 100,00 & 14,29 & 152,39 & 138,11 \\
Capsicodendron dinisii & 13,00 & 5,39 & 1,1315 & 5,15 & 70,00 & 10,00 & 20,55 & 10,55 \\
Ilex dumosa & 11,00 & 4,56 & 0,9945 & 4,53 & 50,00 & 7,14 & 16,24 & 9,09 \\
Campomanesia xanthocarpa & 10,00 & 4,15 & 0,3705 & 1,69 & 60,00 & 8,57 & 14,41 & 5,84 \\
Ocotea porosa & 8,00 & 3,32 & 0,5007 & 2,28 & 50,00 & 7,14 & 12,74 & 5,60 \\
\hline Total & 241,00 & 100,00 & 21,9637 & 100,00 & 700,00 & 100,00 & 300,00 & 200,00 \\
\hline \multicolumn{7}{c}{2000} \\
\hline Araucaria angustifolia & 182,00 & 60,07 & 23,3182 & 74,34 & 100,00 & 12,66 & 147,06 & 134,41 \\
Campomanesia xanthocarpa & 24,00 & 7,92 & 1,0466 & 3,34 & 70,00 & 8,86 & 20,12 & 11,26 \\
Nectandra grandiflora & 21,00 & 6,93 & 1,3049 & 4,16 & 70,00 & 8,86 & 19,95 & 11,09 \\
Capsicodendron dinisii & 9,00 & 2,97 & 0,8989 & 2,87 & 60,00 & 7,59 & 13,43 & 5,84 \\
Rapanea ferruginea & 9,00 & 2,97 & 0,5355 & 1,71 & 60,00 & 7,59 & 12,27 & 4,68 \\
Total & 303,00 & 100,00 & 31,3669 & 100,00 & 790,00 & 100,00 & 300,00 & 200,00 \\
\hline Em que: DA = densidade absoluta; DR densidade relativa; DoA = dominância absoluta; DoR = dominância relativa;
\end{tabular}

TABELA 7: Parâmetros fitossociológicos das cinco principais espécies e do total da parcela 10 em 1979 e 2000.

TABLE 7: Phytosociological parameters of the five principal species and of the total from plot 10, in 1979 and 2000.

\begin{tabular}{|c|c|c|c|c|c|c|c|c|}
\hline Espécies & $\begin{array}{c}\text { DA } \\
\text { N/ha }\end{array}$ & $\begin{array}{c}\text { DR } \\
\% \\
\end{array}$ & $\begin{array}{c}\text { DoA } \\
\mathrm{m}^{2} / \mathrm{ha}\end{array}$ & $\begin{array}{c}\text { DoR } \\
\% \\
\end{array}$ & $\begin{array}{c}\text { FA } \\
\% \\
\end{array}$ & $\begin{array}{c}\text { FR } \\
\% \\
\end{array}$ & V I & $\mathrm{V} \mathrm{C}$ \\
\hline \multicolumn{9}{|c|}{1979} \\
\hline Araucaria angustifólia & 119,00 & 48,57 & 14,4971 & 60,13 & 100,00 & 14,08 & 122,78 & 108,70 \\
\hline Matayba elaeagnoides & 28,00 & 11,43 & 2,8368 & 11,77 & 90,00 & 12,68 & 35,87 & 23,19 \\
\hline Ilex dumosa & 31,00 & 12,65 & 1,8453 & 7,65 & 100,00 & 14,08 & 34,39 & 20,31 \\
\hline Capsicodendron dinisii & 13,00 & 5,31 & 0,9344 & 3,88 & 50,00 & 7,04 & 16,22 & 9,18 \\
\hline Nectandra grandiflora & 13,00 & 5,31 & 0,7655 & 3,18 & 50,00 & 7,04 & 15,52 & 8,48 \\
\hline Total & 245,00 & 100,00 & 24,1114 & 100,00 & 710,00 & 100,00 & 300,00 & 200,00 \\
\hline \multicolumn{9}{|c|}{2000} \\
\hline Araucaria angustifólia & 132,00 & 55,93 & 19,7970 & 68,25 & 100,00 & 14,08 & 138,27 & 124,18 \\
\hline Matayba elaeagnoides & 24,00 & 10,17 & 2,8312 & 9,76 & 90,00 & 12,68 & 32,61 & 19,93 \\
\hline Nectandra grandiflora & 18,00 & 7,63 & 1,1247 & 3,88 & 70,00 & 9,86 & 21,36 & 11,50 \\
\hline Capsicodendron dinisii & 10,00 & 4,24 & 0,9742 & 3,36 & 50,00 & 7,04 & 14,64 & 7,60 \\
\hline Ocotea porosa & 5,00 & 2,12 & 1,5470 & 5,33 & 40,00 & 5,63 & 13,09 & 7,45 \\
\hline Total & 236,00 & 100,00 & 29,0073 & 100,00 & 710,00 & 100,00 & 300,00 & 200,00 \\
\hline
\end{tabular}


TABELA 8: Parâmetros fitossociológicos das cinco principais espécies e do total da parcela 17 em 1979 e 2000.

TABLE 8: Phytosociological parameters of the five principal species and of the total from plot 17, in 1979 and 2000.

\begin{tabular}{l|r|r|r|r|r|r|r|r}
\hline Espécies & $\begin{array}{c}\text { DA } \\
\text { N/ha }\end{array}$ & $\begin{array}{c}\text { DR } \\
\%\end{array}$ & $\begin{array}{c}\text { DoA } \\
\mathrm{m}^{2} / \mathrm{ha}\end{array}$ & $\begin{array}{c}\text { DoR } \\
\%\end{array}$ & $\begin{array}{c}\text { FA } \\
\%\end{array}$ & $\begin{array}{c}\text { FR } \\
\%\end{array}$ & V I & V C \\
\hline \multicolumn{7}{c}{1979} \\
\hline Araucaria angustifólia & 71,00 & 29,58 & 8,3069 & 34,74 & 100,00 & 11,36 & 75,69 & 64,32 \\
Matayba elaeagnoides & 44,00 & 18,33 & 4,8383 & 20,23 & 90,00 & 10,23 & 48,80 & 38,57 \\
Ilex dumosa & 42,00 & 17,50 & 2,2592 & 9,45 & 100,00 & 11,36 & 38,31 & 26,95 \\
Ocotea porosa & 13,00 & 5,42 & 3,0356 & 12,70 & 80,00 & 9,09 & 27,20 & 18,11 \\
Ocotea corymbosa & 14,00 & 5,83 & 1,7460 & 7,30 & 70,00 & 7,95 & 21,09 & 13,14 \\
\hline Total & 240,00 & 100,00 & 23,9107 & 100,00 & 880,00 & 100,00 & 300,00 & 200,00 \\
\hline \multicolumn{7}{c}{2000} \\
Araucaria angustifólia & 86,00 & 37,55 & 13,1073 & 43,77 & 100,00 & 11,49 & 92,82 & 81,32 \\
Matayba elaeagnoides & 39,00 & 17,03 & 5,1363 & 17,15 & 90,00 & 10,34 & 44,53 & 34,18 \\
Ocotea porosa & 14,00 & 6,11 & 3,8442 & 12,84 & 80,00 & 9,20 & 28,15 & 18,95 \\
Ocotea corymbosa & 15,00 & 6,55 & 2,4302 & 8,12 & 70,00 & 8,05 & 22,71 & 14,67 \\
Capsicodendron dinisii & 17,00 & 7,42 & 0,8870 & 2,96 & 80,00 & 9,20 & 19,58 & 10,39 \\
\hline Total & 229,00 & 100,00 & 29,9467 & 100,00 & 870,00 & 100,00 & 300,00 & 200,00 \\
\hline
\end{tabular}

Em que: $\mathrm{DA}=$ densidade absoluta; $\mathrm{DR}=$ densidade relativa; $\mathrm{DoA}=$ dominância absoluta; DoR $=$ dominância relativa; $\mathrm{FA}=$ freqüência absoluta; $\mathrm{FR}=$ frequiência relativa; $\mathrm{VI}=$ valor de importância; $\mathrm{VC}=$ valor de cobertura.

TABELA 9: Parâmetros fitossociológicos das cinco principais espécies e do total da parcela 18 em 1979 e 2000.

TABLE 9: Phytosociological parameters of the five principal species and of the total from plot 18, in 1979 and 2000.

\begin{tabular}{l|r|r|r|r|r|r|r|r}
\hline Espécies & $\begin{array}{c}\text { DA } \\
\text { N/ha }\end{array}$ & $\begin{array}{c}\text { DR } \\
\%\end{array}$ & $\begin{array}{c}\text { DoA } \\
\mathrm{m}^{2} / \mathrm{ha}\end{array}$ & $\begin{array}{c}\text { DoR } \\
\%\end{array}$ & $\begin{array}{c}\text { FA } \\
\%\end{array}$ & $\begin{array}{c}\text { FR } \\
\%\end{array}$ & V I & V C \\
\hline \multicolumn{10}{c}{1979} \\
\hline Araucaria angustifólia & 141,00 & 51,46 & 15,9566 & 62,97 & 100,00 & 13,16 & 127,59 & 114,43 \\
Ilex dumosa & 51,00 & 18,61 & 3,1861 & 12,57 & 100,00 & 13,16 & 44,34 & 31,19 \\
Capsicodendron dinisii & 22,00 & 8,03 & 1,3342 & 5,27 & 90,00 & 11,84 & 25,14 & 13,29 \\
Matayba elaeagnoides & 10,00 & 3,65 & 1,0986 & 4,34 & 70,00 & 9,21 & 17,20 & 7,98 \\
Lithraea brasiliensis & 11,00 & 4,01 & 0,6763 & 2,67 & 70,00 & 9,21 & 15,89 & 6,68 \\
\hline Total & 274,00 & 100,00 & 25,3399 & 100,00 & 760,00 & 100,00 & 300,00 & 200,00 \\
\hline \multicolumn{7}{c}{2000} \\
Araucaria angustifólia & 167,00 & 63,98 & 22,7205 & 76,31 & 100,00 & 14,29 & 154,58 & 140,29 \\
Capsicodendron dinisii & 24,00 & 9,20 & 1,6556 & 5,56 & 90,00 & 12,86 & 27,61 & 14,76 \\
Nectandra grandiflora & 12,00 & 4,60 & 0,5923 & 1,99 & 80,00 & 11,43 & 18,02 & 6,59 \\
Matayba elaeagnoides & 8,00 & 3,07 & 0,9110 & 3,06 & 70,00 & 10,00 & 16,12 & 6,12 \\
Campomanesia xanthocarpa & 9,00 & 3,45 & 0,5778 & 1,94 & 60,00 & 8,57 & 13,96 & 5,39 \\
\hline Total & 261,00 & 100,00 & 29,7754 & 100,00 & 700,00 & 100,00 & 300,00 & 200,00 \\
\hline
\end{tabular}

Em que: $\mathrm{DA}=$ densidade absoluta; $\mathrm{DR}=$ densidade relativa; $\mathrm{DoA}=$ dominância absoluta; DoR = dominância relativa;

$\mathrm{FA}=$ freqüência absoluta; $\mathrm{FR}=$ freqüência relativa; $\mathrm{VI}=$ valor de importância; $\mathrm{VC}=$ valor de cobertura. 
TABELA 10: Parâmetros fitossociológicos das cinco principais espécies e do total da parcela 21 em 1979 e 2000.

TABLE 10: Fitossociologic parameters of the five principal species and of the total from plot 21, in 1979 and 2000.

\begin{tabular}{|c|c|c|c|c|c|c|c|c|}
\hline Espécies & $\begin{array}{c}\text { DA } \\
\text { N/ha }\end{array}$ & $\begin{array}{c}\text { DR } \\
\%\end{array}$ & $\begin{array}{c}\text { DoA } \\
\mathrm{m}^{2} / \mathrm{ha}\end{array}$ & $\begin{array}{c}\text { DoR } \\
\%\end{array}$ & $\begin{array}{c}\text { FA } \\
\%\end{array}$ & $\begin{array}{c}\text { FR } \\
\%\end{array}$ & V I & $\mathrm{V} \mathrm{C}$ \\
\hline \multicolumn{9}{|c|}{1979} \\
\hline Araucaria angustifólia & 70,00 & 31,82 & 7,1470 & 34,81 & 100,00 & 12,82 & 79,45 & 66,63 \\
\hline Ilex dumosa & 53,00 & 24,09 & 3,4437 & 16,77 & 90,00 & 11,54 & 52,40 & 40,87 \\
\hline Matayba elaeagnoides & 19,00 & 8,64 & 2,6437 & 12,88 & 80,00 & 10,26 & 31,77 & 21,51 \\
\hline Rapanea ferruginea & 24,00 & 10,91 & 1,5217 & 7,41 & 90,00 & 11,54 & 29,86 & 18,32 \\
\hline Ocotea porosa & 10,00 & 4,55 & 1,5348 & 7,48 & 70,00 & 8,97 & 21,00 & 12,02 \\
\hline Total & 220,00 & 100,00 & 20,5286 & 100,00 & 780,00 & 100,00 & 300,00 & 200,00 \\
\hline \multicolumn{9}{|c|}{2000} \\
\hline Araucaria angustifólia & 88,00 & 38,26 & 11,1275 & 46,48 & 100,00 & 10,64 & 95,38 & 84,74 \\
\hline Nectandra grandiflora & 28,00 & 12,17 & 2,1544 & 9,00 & 90,00 & 9,57 & 30,75 & 21,17 \\
\hline Matayba elaeagnoides & 18,00 & 7,83 & 2,6533 & 11,08 & 70,00 & 7,45 & 26,36 & 18,91 \\
\hline Rapanea ferruginea & 18,00 & 7,83 & 1,4720 & 6,15 & 80,00 & 8,51 & 22,49 & 13,97 \\
\hline Ocotea porosa & 10,00 & 4,35 & 2,0597 & 8,60 & 70,00 & 7,45 & 20,40 & 12,95 \\
\hline Total & 230,00 & 100,00 & 23,9409 & 100,00 & 940,00 & 100,00 & 300,00 & 200,00 \\
\hline
\end{tabular}

TABELA 11: Parâmetros fitossociológicos das cinco principais espécies e do total da parcela 22 em 1979 e 2000.

TABLE 11: Fitossociologic parameters of the five principal species and of the total from plot 22, in 1979 and 2000.

\begin{tabular}{|c|c|c|c|c|c|c|c|c|}
\hline Espécies & $\begin{array}{c}\text { DA } \\
\text { N/ha }\end{array}$ & $\begin{array}{c}\text { DR } \\
\%\end{array}$ & $\begin{array}{c}\text { DoA } \\
\mathrm{m}^{2} / \mathrm{ha}\end{array}$ & $\begin{array}{c}\text { DoR } \\
\%\end{array}$ & $\begin{array}{c}\text { FA } \\
\%\end{array}$ & $\begin{array}{c}\text { FR } \\
\%\end{array}$ & V I & V C \\
\hline \multicolumn{9}{|c|}{1979} \\
\hline Araucaria angustifólia & 87,00 & 38,16 & 11,7942 & 47,14 & 100,00 & 9,90 & 95,20 & 85,29 \\
\hline Nectandra grandiflora & 17,00 & 7,46 & 1,7920 & 7,16 & 70,00 & 6,93 & 21,55 & 14,62 \\
\hline Prunus brasiliensis & 20,00 & 8,77 & 1,1560 & 4,62 & 70,00 & 6,93 & 20,32 & 13,39 \\
\hline Matayba elaeagnoides & 13,00 & 5,70 & 1,8557 & 7,42 & 70,00 & 6,93 & 20,05 & 13,12 \\
\hline Ilex brevicuspis & 15,00 & 6,58 & 1,6541 & 6,61 & 60,00 & 5,94 & 19,13 & 13,19 \\
\hline Total & 228,00 & 100,00 & 25,0212 & 100,00 & 1010,00 & 100,00 & 300,00 & 200,00 \\
\hline \multicolumn{9}{|c|}{2000} \\
\hline Araucaria angustifólia & 113,00 & 46,89 & 17,3254 & 58,25 & 100,00 & 10,20 & 115,35 & 105,14 \\
\hline Nectandra grandiflora & 18,00 & 7,47 & 2,0623 & 6,93 & 90,00 & 9,18 & 23,59 & 14,40 \\
\hline Prunus brasiliensis & 15,00 & 6,22 & 1,1117 & 3,74 & 80,00 & 8,16 & 18,13 & 9,96 \\
\hline Matayba elaeagnoides & 10,00 & 4,15 & 1,7228 & 5,79 & 50,00 & 5,10 & 15,04 & 9,94 \\
\hline Ocotea porosa & 8,00 & 3,32 & 1,9994 & 6,72 & 40,00 & 4,08 & 14,12 & 10,04 \\
\hline Total & 241,00 & 100,00 & 29,7411 & 100,00 & 980,00 & 100,00 & 300,00 & 200,00 \\
\hline
\end{tabular}


TABELA 12: Parâmetros fitossociológicos das cinco principais espécies e do total da parcela 30 em 1979 e 2000.

TABLE 12: Phytosociological parameters of the five principal species and of the total from plot 30, in 1979 and 2000.

\begin{tabular}{l|r|r|r|r|r|r|r|r}
\hline Espécies & $\begin{array}{c}\text { DA } \\
\text { N/ha }\end{array}$ & $\begin{array}{c}\text { DR } \\
\%\end{array}$ & $\begin{array}{c}\text { DoA } \\
\mathrm{m}^{2} / \mathrm{ha}\end{array}$ & $\begin{array}{c}\text { DoR } \\
\%\end{array}$ & $\begin{array}{c}\text { FA } \\
\%\end{array}$ & $\begin{array}{c}\text { FR } \\
\%\end{array}$ & V I & V C \\
\hline Araucaria angustifólia & 78,00 & 28,57 & 8,9667 & 27,35 & 100,00 & 8,93 & 64,85 & 55,92 \\
Ocotea porosa & 16,00 & 5,86 & 6,0262 & 18,38 & 90,00 & 8,04 & 32,28 & 24,24 \\
Ilex brevicuspis & 31,00 & 11,36 & 3,2698 & 9,97 & 100,00 & 8,93 & 30,26 & 21,33 \\
Matayba elaeagnoides & 22,00 & 8,06 & 3,1944 & 9,74 & 90,00 & 8,04 & 25,84 & 17,80 \\
Ilex dumosa & 27,00 & 9,89 & 1,6120 & 4,92 & 90,00 & 8,04 & 22,84 & 14,81 \\
\hline Total & 273,00 & 100,00 & 32,7872 & 100,00 & 1120,00 & 100,00 & 300,00 & 200,00 \\
\hline \multicolumn{7}{c}{2000} \\
Araucaria angustifólia & 97,00 & 35,93 & 13,4547 & 36,48 & 100,00 & 9,17 & 81,58 & 72,41 \\
Ocotea porosa & 17,00 & 6,30 & 6,9499 & 18,84 & 90,00 & 8,26 & 33,40 & 25,14 \\
Matayba elaeagnoides & 19,00 & 7,04 & 3,4507 & 9,36 & 80,00 & 7,34 & 23,73 & 16,39 \\
Campomanesia xanthocarpa & 25,00 & 9,26 & 2,1894 & 5,94 & 90,00 & 8,26 & 23,45 & 15,20 \\
Nectandra grandiflora & 25,00 & 9,26 & 2,2908 & 6,21 & 80,00 & 7,34 & 22,81 & 15,47 \\
\hline Total & 270,00 & 100,00 & 36,8828 & 100,00 & 1090,00 & 100,00 & 300,00 & 200,00 \\
\hline
\end{tabular}

Em que: $\mathrm{DA}=$ densidade absoluta; $\mathrm{DR}=$ densidade relativa; DoA = dominância absoluta; DoR = dominância relativa; $\mathrm{FA}=$ freqüência absoluta; $\mathrm{FR}$ = freqüência relativa; $\mathrm{VI}=$ valor de importância; $\mathrm{VC}=$ valor de cobertura.

De maneira geral, excluindo-se a parcela 7, em todos as outras, a importância relativa da Araucaria angustifolia aumentou entre 1979 e 2000.

Ao analisar-se a dominância absoluta, nota-se que esse parâmetro talvez não sirva como um bom indicador de produtividade para a comunidade em questão, pois, embora seu valor varie de parcela para parcela, também é variável ao longo do tempo:

a) em 1979, a área basal das parcelas variou de 16,82 (parcela 1) a $32,79 \mathrm{~m}^{2} /$ ha (parcela 30 ), seguindo a seguinte ordenação das parcelas: $1,21,6,7,17,10,22,18$ e 30 ;

b) em 2000, a área basal das parcelas variou de 19,43 (parcela 1) a $36,88 \mathrm{~m}^{2} /$ ha (parcela 30 ), seguindo a ordem das parcelas: $1,21,6,10,22,18,17,7$ e 30 .

O fato de o grau de dominância entre as parecelas ter variado ao longo do tempo, isto é, uma parcela com área basal maior que a outra em 1979, apresentar área basal menor em 2000, provavelmente ocorreu em conseqüência do fato de a comunidade ainda se encontrar em desenvolvimento. Isso indica que a dominância serve como indicador de produtividade apenas para comunidades maduras, isto é, que ocupem integralmente a capacidade produtiva do habitat, ou para comunidades que se encontrem no mesmo estágio de desenvolvimento sucessional, o que é de difícil determinação.

Outra constatação a respeito da dominância absoluta é que, seguindo o mesmo padrão mostrado pela comunidade (análise com todas as parcelas juntas), todos as parcelas aumentaram o grau de ocupação. Contudo, o grau do aumento na área basal foi variável. Em termos absolutos, a parcela 1 foi a que apresentou o menor aumento no grau de ocupação, passando de 16,82 $\mathrm{m}^{2}$, em 1979, para 19,43 m², em 2000, ou seja, uma acréscimo de $2,61 \mathrm{~m}^{2}$ de material lenhoso no período. Por outro lado, a parcela 7 foi o que apresentou o maior aumento, passando de 21,96 $\mathrm{m}^{2}$ em 1979, para 31,37 $\mathrm{m}^{2}$ em 2000, ou seja, um acréscimo de 9,40 $\mathrm{m}^{2}$ de material lenhoso no período. Em termos relativos, a parcela 7 também apresentou o maior aumento $(42,81 \%)$ da área basal. Entretanto, contrariando o resultado em termos absolutos, foi a parcela 30 que apresentou o menor aumento relativo $(12,49 \%)$ e não a parcela $1(15,52 \%)$, provavelmente indicando que está se aproximando da capacidade máxima de ocupação do habitat.

A análise da evolução da ocupação do terreno em termos relativos fornece uma visão mais realista do que a análise em termos absolutos. Isso se deve ao fato de as parcelas terem produtividades e qualidades de habitat diferenciadas. Por exemplo, se for considerado que, em um mesmo período de tempo, a área basal de 
duas parcelas aumentou $2 \mathrm{~m}^{2}$, sendo que a primeira parcela pode atingir $40 \mathrm{~m}^{2}$ de área basal máxima e a segunda $20 \mathrm{~m}^{2}$, conclui-se que havia, proporcionalmente, muito mais espaço de crescimento disponível na segunda parcela do que para a primeira, ou seja, a primeira parcela provavelmente se encontrava num estágio sucessional mais avançado que a segunda. Em decorrência, a recuperação da biomassa ou da área basal pode ser utilizada como um critério de restauração da comunidade (Corlett, 1995).

\section{Diversidade}

$\mathrm{Na}$ Tabela 13, pode ser observado o resultado de alguns índices de diversidade calculados para a comunidade estudada nos anos de 1979 e 2000.

Apesar de o quociente de mistura de Jentsch ter sido de 0,02, o número de indivíduos por espécie diminuiu no período estudado: em 1979 havia aproximadamente 42 indivíduos/espécie e, em 2000, quarenta indivíduos/espécie.

Se o quociente de mistura de Jentsch, que considera linear a relação entre o número de espécies e o número de indivíduos, mostrou-se ineficiente para detectar o aumento de riqueza, os índices de Margalef e de Odum, que consideram logarítmica a relação espécie/indivíduos, acusaram essa variação. Margalef registrou variações positivas de 7,7\% em seu índice $(6,52$ para 7,02) e Odum 7,5\% (6,65 a 7,15). Esses índices indicam que quanto maior for os seus valores, maior será a diversidade de espécies. Outro índice que apresentou comportamento semelhante foi o índice de Menhinick que considera a relação espécies/indivíduos como sendo quadrática: seu valor aumentou de 1,10 para 1,17 (aumento de 6,4\%), entre 1979 e 2000. A maior sensibilidade em detectar o aumento proporcional do número de espécies ocorrido por esses três últimos índices, quando comparados com o quociente de mistura de Jentsch, deve-se ao fato de que um aumento no número de indivíduos é diretamente proporcional à redução do valor do $Q M$, enquanto que para o os índices de Margalef e Odum a redução é proporcional ao logaritmo neperiano e para o índice de Menhinick à raiz quadrada do número de indivíduos. Os índices de Margalef e Odum mostraram-se bastante semelhantes quanto ao comportamento, pois suas fórmulas são muito parecidas.

TABELA 13: Índices de diversidade para a floresta.

TABLE 13: Diversity indexes for the forest.

\begin{tabular}{|c|c|c|}
\hline \multirow{2}{*}{ Índices de Diversidade } & \multicolumn{2}{|c|}{ Ano } \\
\hline & 1979 & 2000 \\
\hline Número de indivíduos & 2133 & 2202 \\
\hline Número de espécies & 51 & 55 \\
\hline Coeficiente de mistura de Jentsch $(Q M)$ & 0,02 & 0,02 \\
\hline Índice de Margalef & 6,52 & 7,02 \\
\hline Índice de Menhinick & 1,10 & 1,17 \\
\hline Índice de Odum & 6,65 & 7,15 \\
\hline Índice de McIntosh $(U)$ & 108,48 & 124,63 \\
\hline Índice de Simpson $(L)$ & 0,21 & 0,26 \\
\hline Indice de McIntosh $(D)$ & 0,97 & 0,96 \\
\hline
\end{tabular}

A variação do índice $U$ de McIntosh, que aumentou de 108,48 em 1979 para 124,63 em 2000, pode ser creditada:

a) ao aumento da dominância de alguma(s) espécie(s) no ano de 2000, quando comparada a 1979, pois, quanto menor o valor do índice, maior é a uniformidade da comunidade, e mais perto da origem do hiperespaço de $S$ (número de espécies) dimensões estará a comunidade. Se todas as espécies estiverem representadas pelo mesmo número de indivíduos, menor será o valor do índice;

b) ao fato de que o aumento de 69 indivíduos pode ter causado o aumento da distância da comunidade em relação à origem.

O índice de Simpson corrobora a primeira afirmativa, pois, se em 1979, havia 21\% de probabilidade de dois indivíduos sorteados aleatoriamente da floresta pertencerem à mesma espécie, em 2000, essa probabilidade aumentou para $26 \%$, indicando que uma espécie que, no caso desse estudo, é a araucária está cada vez mais dominando a comunidade. O índice $D$ de McIntosh também corrobora para a aceitação da 
primeira afirmativa, mesmo que tenha modificado pouco entre os períodos estudados. O seu cálculo pondera o valor de $U$ pelo número total de indivíduos da comunidade. Assim, como seu valor diminuiu, tem-se que, mesmo com o aumento do número de indivíduos da comunidade, seu afastamento em relação à origem do hiperespaço aumentou. Pois, quanto menor o valor de $D$, maior a dominância da comunidade.

A análise dos índices de diversidade torna-se mais interessante ainda quando é feita considerando-se cada parcela e ano separadamente, conforme a Tabela 14 para o ano de 1979, e a Tabela 15 para o ano de 2000 .

Quando as parcelas são analisadas em termos apenas do número de espécies encontrado para o ano de 1979, conforme a Tabela 14, verifica-se uma grande heterogeneidade florística, sendo a parcela 22 a que apresenta o maior número de espécies e a 1 o menor. Os índices de Margalef e Odum ordenam as parcelas em termos de diversidade na mesma seqüência, sendo a parcela 22 a mais rica e a 1 a mais pobre. Por outro lado, quando se considera o quociente de mistura de Jentsch, a parcela 1 passa a ser a segunda mais rica, pois, apesar de conter o menor número de espécies (19), apresenta uma média de nove indivíduos por espécie, contra 13 indivíduos por espécie na parcela 18, que, no total, tem 21 espécies. A parcela 30, por exemplo, que é a segunda em número de espécies (26), apresenta uma relação de 11 indivíduos/espécie. Isso comprova a fragilidade do quociente de mistura de Jentsch como parâmetro da diversidade, o qual é muito influenciado pelo tamanho da amostra (número de indivíduos).

TABELA 14: Índices de diversidade para as parcelas em 1979.

TABLE 14: Diversity indexes for the plots in 1979.

\begin{tabular}{|c|c|c|c|c|c|c|c|c|c|}
\hline \multirow{2}{*}{ Índices de Diversidade } & \multicolumn{9}{|c|}{ Parcelas } \\
\hline & 1 & 6 & 7 & 10 & 17 & 18 & 21 & 22 & 30 \\
\hline Número de indivíduos & 180 & 232 & 241 & 245 & 240 & 274 & 220 & 228 & 273 \\
\hline Número de espécies & 19 & 20 & 23 & 21 & 25 & 21 & 20 & 33 & 26 \\
\hline Coeficiente de mistura de Jentsch & 0,11 & 0,09 & 0,10 & 0,09 & 0,10 & 0,08 & 0,09 & 0,14 & 0,10 \\
\hline Índice de Margalef & 3,47 & 3,49 & 4,01 & 3,64 & 4,38 & 3,56 & 3,52 & 5,89 & 4,46 \\
\hline Îndice de Menhinick & 1,42 & 1,31 & 1,48 & 1,34 & 1,61 & 1,27 & 1,35 & 2,19 & 1,57 \\
\hline Índice de Odum & 3,66 & 3,67 & 4,19 & 3,82 & 4,56 & 3,74 & 3,71 & 6,08 & 4,64 \\
\hline Indice de McIntosh $(U)$ & 95,11 & 102,80 & 156,03 & 128,15 & 97,11 & 152,78 & 94,83 & 94,84 & 97,41 \\
\hline Indice de Simpson $(L)$ & 0,28 & 0,19 & 0,42 & 0,27 & 0,16 & 0,31 & 0,18 & 0,17 & 0,12 \\
\hline Indice de McIntosh (D) & 0,51 & 0,60 & 0,38 & 0,51 & 0,64 & 0,47 & 0,61 & 0,63 & 0,68 \\
\hline
\end{tabular}

Outro fato interessante é a influência da ponderação do número de indivíduos utilizada em cada índice (número de espécies x número de indivíduos) na hierarquização das parcelas. Como exemplo, tem-se a parcela 18. Enquanto os índices logarítmicos (Margalef e Odum) classificam-na como o $6^{\circ}$ mais diverso, o índice quadrático de Menhinick a classifica como a menos diversa das nove parcelas. Já a parcela 1 é classificada como a mais pobre em termos de diversidade pelos índices logarítmicos, enquanto o índice de Menhinick classifica-a como a quinta mais diversa. O problema está em saber qual classificação é a mais condizente com a realidade.

Quanto à heterogeneidade, analisada sob a ótica do índice de Simpson, nota-se que a parcela mais heterogênea é a 30 , com $12 \%$ de probabilidade de que dois indivíduos sorteadas ao acaso sejam da mesma espécie; a parcela 7 mostra-se a mais homogênea de todas, com $42 \%$ de probabilidade.

Quanto à dominância, analisada pelo do índice $U$ de McIntosh, nota-se que a parcela que apresenta a maior dominância de algumas espécies em relação a outras é a 7, com o valor de $U$ atingindo 156,03; as parcelas 21 e 22 são as que apresentam maior equilíbrio, com valores de $U$ iguais a 94,83 e 94,84 respectivamente. Quando o valor de $U$ é ponderado pela raiz quadrada do número de indivíduos, produzindo o índice $D$ de McIntosh, a hierarquia das parcelas em termos de dominância é a mesma da produzida pelo índice de Simpson.

A análise da riqueza em 2000 (Tabela 15) mostra que a floresta manteve sua heterogeneidade florística entre as parcelas. A parcela que apresenta o maior número de espécies é a 22, com 34 espécies. As parcelas 6 e 18 apresentam o menor número, 19 espécies. Baseando-se no quociente de mistura de Jentsch, verifica-se que a parcela 18 é a que apresenta menor riqueza de espécies, enquanto a 22 é a mais rica. $\mathrm{O}$ 
menor valor do quociente de mistura de Jentsch para a parcela 18 , comparada a 6 , deve-se ao maior número de indivíduos encontrado na primeira. Quando se analisa a evolução da riqueza de espécies ocorrida nas parcelas entre 1979 e 2000, nota-se que 7 parcelas $(1,7,10,17,21,22$ e 30) aumentaram o número de espécies no período e duas (6 e 18) diminuíram. A mudança no número absoluto de espécies não refletiu grandemente no resultado do quociente de mistura. Como exemplo, tem-se a parcela 7, que tinha 23 espécies e 241 indivíduos em 1979, sendo que em 2000 apresentou 27 espécies e 303 indivíduos; o quociente de mistura diminui apenas de 0,10 para 0,09 .

TABELA 15: Índices de diversidade para as parcelas em 2000.

TABLE 15: Diversity indexes for the plots in 2000.

\begin{tabular}{l|r|r|r|r|r|r|r|r|r}
\hline \multirow{1}{*}{\multicolumn{1}{c}{ Índices de Diversidade }} & \multicolumn{10}{c}{ Parcelas } \\
\cline { 2 - 11 } & 1 & 6 & 7 & 10 & 17 & 18 & 21 & 22 & 30 \\
\hline Número de indivíduos & 187 & 245 & 303 & 236 & 229 & 261 & 230 & 241 & 270 \\
Número de espécies & 22 & 19 & 27 & 24 & 28 & 19 & 25 & 34 & 31 \\
Coeficiente de mistura de Jentsch & 0,12 & 0,08 & 0,09 & 0,10 & 0,12 & 0,07 & 0,11 & 0,14 & 0,11 \\
Índice de Margalef & 4,01 & 3,27 & 4,55 & 4,21 & 4,97 & 3,23 & 4,41 & 6,02 & 5,36 \\
Índice de Menhinick & 1,61 & 1,21 & 1,55 & 1,56 & 1,85 & 1,18 & 1,65 & 2,19 & 1,89 \\
Índice de Odum & 4,21 & 3,45 & 4,73 & 4,39 & 5,15 & 3,41 & 4,60 & 6,20 & 5,54 \\
Índice de McIntosh $(U)$ & 114,01 & 114,59 & 185,89 & 136,55 & 99,86 & 170,05 & 98,51 & 117,70 & 109,09 \\
Índice de Simpson $(L)$ & 0,37 & 0,22 & 0,37 & 0,33 & 0,19 & 0,42 & 0,18 & 0,24 & 0,16 \\
Índice de McIntosh $(D)$ & 0,42 & 0,57 & 0,41 & 0,45 & 0,60 & 0,37 & 0,61 & 0,55 & 0,63 \\
\hline
\end{tabular}

Da mesma forma que o ocorrido em 1979, os índices de Margalef e Odum ordenaram as parcelas seguindo a mesma seqüência, confirmando tratarem-se de índices que se sobrepõem, ou seja, pode-se escolher tanto um como o outro para efetuar os cálculos de riqueza, pois medem a mesma coisa. Entretanto, a ordem em que as parcelas foram classificadas em 2000 se alterou. A parcela mais pobre, por esses índices, no ano 2000, é a 18 e, em 1979, era a parcela 1. É importante notar que todas as parcelas, cujo número absoluto de espécies cresceu, aumentaram os valores dos índices de Margalef e Odum. Esse comportamento também foi observado para o índice de Menhinick. Com relação a esse índice, observa-se que a classificação das parcelas em termos de riqueza de espécies proporcionada por ele foi bem mais coerente com a gerada pelos índices de Margalef e Odum em 2000 do que em 1979. A única diferença em 2000 ocorreu na classificação das parcelas 1, 7 e 21. Pelo índice de Menhinick, a parcela 1 é a $5^{a}$ mais diversa e pelos outros dois índices é a $7^{\mathrm{a}}$. A parcela 7 , pelo índice de Menhinick, é a $7^{\mathrm{a}}$, pelo outros é a $4^{\mathrm{a}}$. Já a parcela 21 é considerado a $4^{\mathrm{a}}$ mais diversa por Menhinick e a $5^{\text {a }}$ pelo outros dois índices.

Se por um lado, em 2000, foram constatadas diferenças na classificação de três parcelas, em 1979, foram constatadas diferenças na classificação de seis $(1,10,17,18,21$ e 30). Quanto à heterogeneidade e à dominância, verificou-se que o índice $U$ de McIntosh aumentou de valor para todas as parcelas em $2000 \mathrm{em}$ relação a 1979. Isso confirma o aumento da dominância de uma espécie na floresta. O índice de Simpson aumentou para todas as parcelas entre 1979 e 2000, excetuando-se a parcela 7 cujo valor diminuiu (de 0,42 para 0,37$)$ e a 21 que permaneceu com o mesmo valor $(0,18)$.

O índice $D$ de McIntosh acompanhou o comportamento do índice de Simpson, entretanto em vez de aumentar diminuiu, mas a interpretação da variação dos índices é a mesma. Se o aumento do índice de Simpson indica homogeneização e aumento da dominância, a diminuição do índice $D$ de McIntosh possui a mesma interpretação. Tanto que as mesmas parcelas em que o valor do índice de Simpson diminuiu (7) ou permaneceu constante (21), o valor do índice $D$ de McIntosh, respectivamente, aumentou e permaneceu constante. Além disso, a classificação das parcelas com base nos dois índices é a mesma, o que repete o resultado obtido em 1979 e confirma a semelhança entre eles.

Em relação ao comportamento geral dos índices utilizados nos dois levantamentos, observou-se que os melhores índices para representar a diversidade são os que consideram tanto a quantidade de espécies (riqueza) como a uniformidade da distribuição da densidade, ou seja, os índices de Simpson, $U$ e $D$ de McIntosh, sendo que o comportamento do último é semelhante ao apresentado pelo índice de Simpson.

Os índices de Simpson e $U$ de McIntosh mostraram-se ser influenciáveis pelo tamanho da amostra, 
isto é, seus valores tiveram um comportamento mais estável quando compara-se a comunidade às parcelas. Nesse sentido, tais índices apresentaram comportamento oposto aos índices de Margalef, Odum e Menhinick.

Talvez seja mais coerente utilizar o valor do índice de Simpson $(L)$ subtraído de um $(1-L)$ como medida de diversidade, como propõem alguns autores, pois um aumento no valor de $L$ significa uma diminuição da diversidade. Assim, utilizando-se $(1-L)$ o valor do índice aumenta junto com a diversidade. Entretanto, a análise utilizando-se $L$ produz os mesmos resultados da análise utilizando-se " $1-L$ ", sendo que a única diferença reside na interpretação do valor apresentado pelo índice.

Durigan (1999) utilizou o índice de Simpson, calculado pela fórmula "1 - L", para analisar a heterogeneidade das parcelas $6,14,16$ e 28 , encontrando os valores $0,89,0,95,0,92$ e 0,94 respectivamente, ou seja, $0,11,0,05,0,08$ e 0,06 , se considerar-se o valor de $L$. Quando comparados aos valores apresentados neste trabalho, verifica-se uma maior heterogeneidade florística encontrada pela referida autora. Como exemplo tem-se a parcela 6 - única comum aos dois trabalhos -, neste estudo apresentou um valor de $L$ igual a 0,22 para o ano 2000 (Tabela 4), enquanto Durigan (1999) encontrou um valor de $L$ igual a 0,11 .

Contudo, deve-se levar em conta que, enquanto neste estudo foram computadas, em média, 25 espécies por parcela (19 na parcela 6), a referida autora encontrou, em média, 47 espécies por parcela (45 na parcela 6). Tal diferença se deve ao diâmetro mínimo considerado nos dois levantamentos: $20 \mathrm{~cm}$ neste trabalho e $10 \mathrm{~cm}$ em Durigan (1999).

Portanto, considerando-se novamente a parcela 6 , verifica-se que se o diâmetro mínimo de inclusão passar de 10 para $20 \mathrm{~cm}$, a probabilidade de dois indivíduos, escolhidos ao acaso, serem da mesma espécie dobra, passando de 0,11 para 0,22 , ou seja, a heterogeneidade diminui com o aumento do diâmetro considerado.

\section{CONCLUSÕES}

Com base nas informações obtidas sobre a florística e estrutura no período compreendido entre 1979 e 2000 de uma Floresta Ombrófila Mista, é possível concluir que:

Em 1979, foram encontradas 2133 árvores de 51 espécies pertencentes a 29 famílias, sendo Araucariaceae, Aquifoliaceae, Lauraceae, Sapindaceae, Myrtaceae e Canellaceae as famílias mais importantes da floresta. No levantamento realizado em 2000, foram encontradas 2.202 árvores pertencentes a 55 espécies, pertecentes a 31 famílias;

As famílias mais representativas da floresta em termos de número de árvores não se alteraram entre 1979 e 2000, mas sua ordem de importância na estrutura da floresta sim. A família Aquifoliaceae, que, em 1979, era a segunda em importância, passou para a $6^{a}$ posição no ano 2000.

Todas as famílias presentes em 1979 continuaram na floresta no ano 2000, entretanto duas novas famílias ingressaram na floresta no período: Fabaceae e Proteaceae, cada uma representada por uma única espécie e um único indivíduo.

Da mesma forma que em 1979, a maioria das famílias foi representada por apenas uma espécie em 2000, sendo que apenas 7 famílias, as mesmas de 1979, das 31 famílias encontradas em 2000, apresentaram mais de uma espécie, com destaque para a família Myrtaceae com nove e dez espécies respectivamente, em 1979 e 2000.

Das 51 espécies presentes em 1979, duas não foram encontradas em 2000: Baccharis elaeagnoides e Scutia buxifolia. Contudo, seis espécies ingressaram na floresta no período: Vernonia discolor, Dalbergia brasiliensis, Campomanesia guazumifolia, Roupala brasiliensis, Hovenia dulcis e Cupania vernalis.

Embora nas duas ocasiões houvesse mais de 50 espécies, apenas sete (Araucaria angustifolia, Ilex dumosa, Matayba elaeagnoides, Ocotea porosa, Capsicodendron dinisii, Nectandra grandiflora e Campomanesia xanthocarpa) representavam 80,36\% dos indivíduos em 1979 e, no ano 2000, as mesmas sete espécies mais Ocotea corymbosa responderam por $80,88 \%$ do número total de indivíduos.

Houve muitas mudanças na freqüência de árvores no período analisado. Algumas espécies diminuiram drásticamente o número de indivíduos (Ilex dumosa, Ilex brevicuspis) enquanto outras tiveram aumentos importantes, como Ilex paraguariensis e Syagrus romanzoffiana. 
Todos os indicadores estruturais analisados mostraram que a floresta amadureceu no período 19792000, ou seja, não se encontrava num estágio sucessional muito avançado em 1979. Se ela já atingiu esse estágio em 2000, só futuros estudos vão comprovar. Mostram ainda que a dominância de Araucaria angustifolia se acentuou no período estudado, sendo bem provável que tal dominância venha a aumentar ainda mais, no futuro.

Ao analisar-se a dominância absoluta nota-se que houve um aumento sensível no grau de ocupação da floresta no período, com o valor saltando de $23,52 \mathrm{~m}^{2} / \mathrm{ha}$ em 1979 para $28,53 \mathrm{~m}^{2} / \mathrm{ha} \mathrm{em} 2000$, ou seja, houve um aumento de $21,3 \%$. Isso indica que a floresta ainda está em processo de desenvolvimento, ou seja, em 1979, ainda não estava madura, ou completamente estocada;

Hovenia dulcis (uva-do-japão) apareceu na estrutura da floresta. Em 1979, não foi constatada a presença de nenhum indivíduo dessa espécie com DAP superior a $20 \mathrm{~cm}$, já em 2000 oito indivíduos foram encontrados. Essa espécie exótica superou muitas espécies nativas na sua participação, demostrando sua agressividade como contaminadora biológica.

O quociente de mistura de Jentsch não detectou as mudanças na riqueza de espécies da floresta. Por outro lado, os índices de Margalef, Odum e Menhinick detectaram o incremento no número de espécies ocorrido na floresta entre 1979 e 2000.

Em relação ao comportamento geral dos índices utilizados nos dois levantamentos, observou-se que os melhores índices para representar a diversidade são os que consideram tanto à quantidade de espécies (riqueza) como a uniformidade da distribuição da densidade, ou seja, os índices de Simpson, $U$ e $D$ de McIntosh, os quais tiveram comportamentos semelhantes.

\section{REFERÊNCIAS BIBLIOGRÁFICAS}

CASTElla, P. R.; BRITEZ, R. M. de. A floresta com araucária no Paraná: conservação e diagnóstico dos remanescentes florestais. Curitiba: Fundação de Pesquisas Florestais do Paraná; Brasília: Ministério do Meio Ambiente, 2004. 236p.

CORLETT,R. T. Tropical secondary forests. Progress in Physical Geography, v. 19, n. 2, p.159-172, 1995.

CRONQUIST, A. An integrated system of classification of flowering plants. New York: Columbia University Press, 1981.

DURIGAN, M. E. Florística, dinâmica e análise protéica de uma floresta ombrófila mista em São João do Triunfo-PR. Curitiba, 1999. 125f. Dissertação (Mestrado em Engenharia Florestal) - Setor de Ciências Agrárias, Universidade Federal do Paraná, Curitiba, 1999.

FUNDAÇÃO INSTITUTO BRASILEIRO DE GEOGRAFIA E ESTATÍSTICA. Departamento de Recursos Naturais e Estudos Ambientais. Manual técnico da vegetação brasileira. Rio de Janeiro: IBGE, 1992. 92p. (Série Manuais Técnicos em Geociências, n.1)

GOLDSMITH, F. B.; HARRISON, C. M. Description and analysis of vegetation. In : CHAPMAN, S. B. (Ed.) Methods in plant ecology. London: Blackwell, 1976. p. 85-155.

HULBERT S.H. The nonconcept of species diversity: a critique and alternative parameters. Ecology, New York, v. 52, n. 4, p. 577-586, 1971.

KIMMINS, J. P. Forest ecology. New York: MacMillan, 1987. 531p.

KOCK, Z.; CORRÊA, M. C. Araucária: a floresta do Brasil meridional. Curitiba: Olhar Brasileiro, 2002. 148p.

LAMPRECHT, H. Ensayo sobre la estructura florística de la parte sur-oriental del Bosque Universitario "El Calmital" Estado Barinas. Rev. For. Venez., Mérida, v. 7, n. 10-11, p. 77-119, 1964.

LEITE, P.F.; KLEIN, R.M. Vegetação. In: LEITE, P.F.; KLEIN, R.M. Geografia do Brasil : Região Sul. Rio de Janeiro: IBGE, 1990. v. 2 .

LONGHI, S. J. A estrutura de uma floresta natural de Araucaria angustifolia (Bert.) O. Ktze, no sul do Brasil. Curitiba, 1980. 198f. Dissertação (Mestrado em Engenharia Florestal) - Setor de Ciências Agrárias, Universidade Federal do Paraná, Curitiba, 1980.

LORENZI, H.; SOUZA, H. M.; TORRES, M. A. V.; BACHER, L. B. Árvores exóticas no Brasil: madeireiras, ornamentais e aromáticas. São Paulo: Nova Odessa, 2003.368p. 
MUELLER-DOMBOIS, D.; ELLENBERG, H. Aims and methods of vegetation ecology. New York: John Wiley \& Sons, 547p. 1974.

ODUM, E.P. Ecologia. Rio de Janeiro: Guanabara Koogan, 1988.

PEET, R.K. The measurements os species diversity. Ann. Rev. Ecol. Syst., v. 5, p. 285-308, 1974.

PIZATTO, W. Avaliação biométrica da estrutura e da dinâmica de uma floresta ombrófila mista em São João do Triunfo-PR: 1995 a 1998. Curitiba, 1999. 172f. Dissertação (Mestrado em Engenharia Florestal) - Setor de Ciências Agrárias, Universidade Federal do Paraná, Curitiba, 1999.

RODRÍGUEZ TELLO, J.C. Eficiência e custos de diferentes formas e tamanhos de unidades de amostra em uma floresta nativa de Araucaria angustifolia (Bert.) o Ktze no sul do Brasil. Curitiba, 1980. Dissertação (Mestrado em Engenharia Florestal) - Setor de Ciências Agrárias, Universidade Federal do Paraná, Curitiba, 1980.

SCHAAF, L. B. Florística, estrutura e dinâmica no período 1979-2000 de uma floresta ombrófila mista localizada no Sul do Paraná. Curitiba, 2001. 131f. Dissertação (Mestrado em Engenharia Florestal) - Setor de Ciências Agrárias, Universidade Federal do Paraná, Curitiba, 2001. 